\title{
Anionic Polymerization of Azidoalkyl Glycidyl Ethers and Post-Polymerization Modification
}

\author{
Joonhee Lee, ${ }^{1,2}$ Sohee Han, ${ }^{1}$ Minseong Kim, ${ }^{1,2}$ and Byeong-Su Kim ${ }^{1 *}$ \\ ${ }^{1}$ Department of Chemistry, Yonsei University, Seoul 03722, Republic of Korea \\ ${ }^{2}$ Department of Chemistry, Ulsan National Institute of Science and Technology (UNIST), \\ Ulsan 44919, Republic of Korea
}

E-mail: bskim19@yonsei.ac.kr

\section{Contents}

Representative ${ }^{1} \mathrm{H},{ }^{13} \mathrm{C}$ NMR Spectra and SEC Trace of P(AHGE) .................................S2-S3

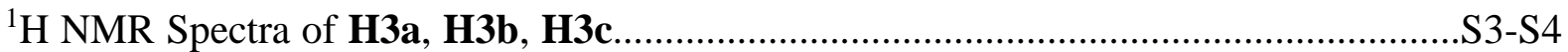

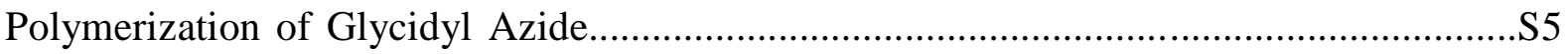

Synthesis and Characterization of a Series of Azidoalkyl Glycidyl Ethers....................S6-S14

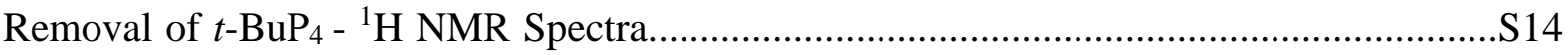

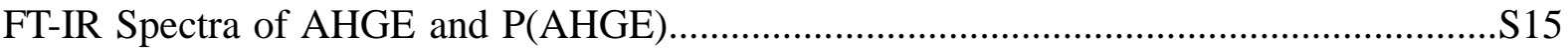

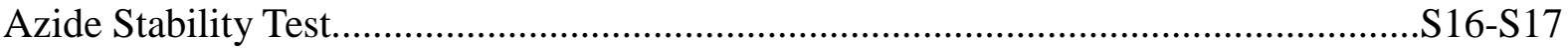

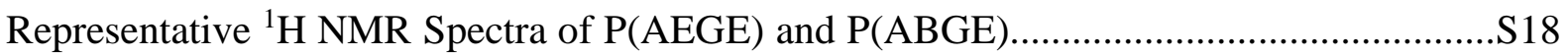

Results of in situ ${ }^{1}$ H NMR Polymerization Kinetics Study.................................................... 19

The Effect of Hydrophobicity on Polymerization Rate..................................................S20

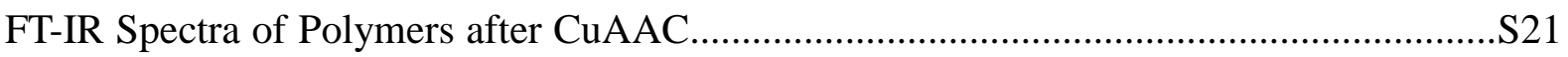

${ }^{1}$ H NMR Spectra of Reduced Polymers (H2a-H2c and PAm) ..................................S21-S23

${ }^{1} \mathrm{H}$ NMR Spectra of P(AHGE)- $b$-P(AGE) and P(AHGE-co-AGE) ..................................... 24

Additional Data and Experimental Procedure .........................................................S25-S26

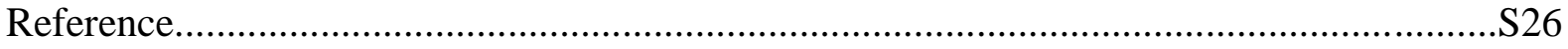




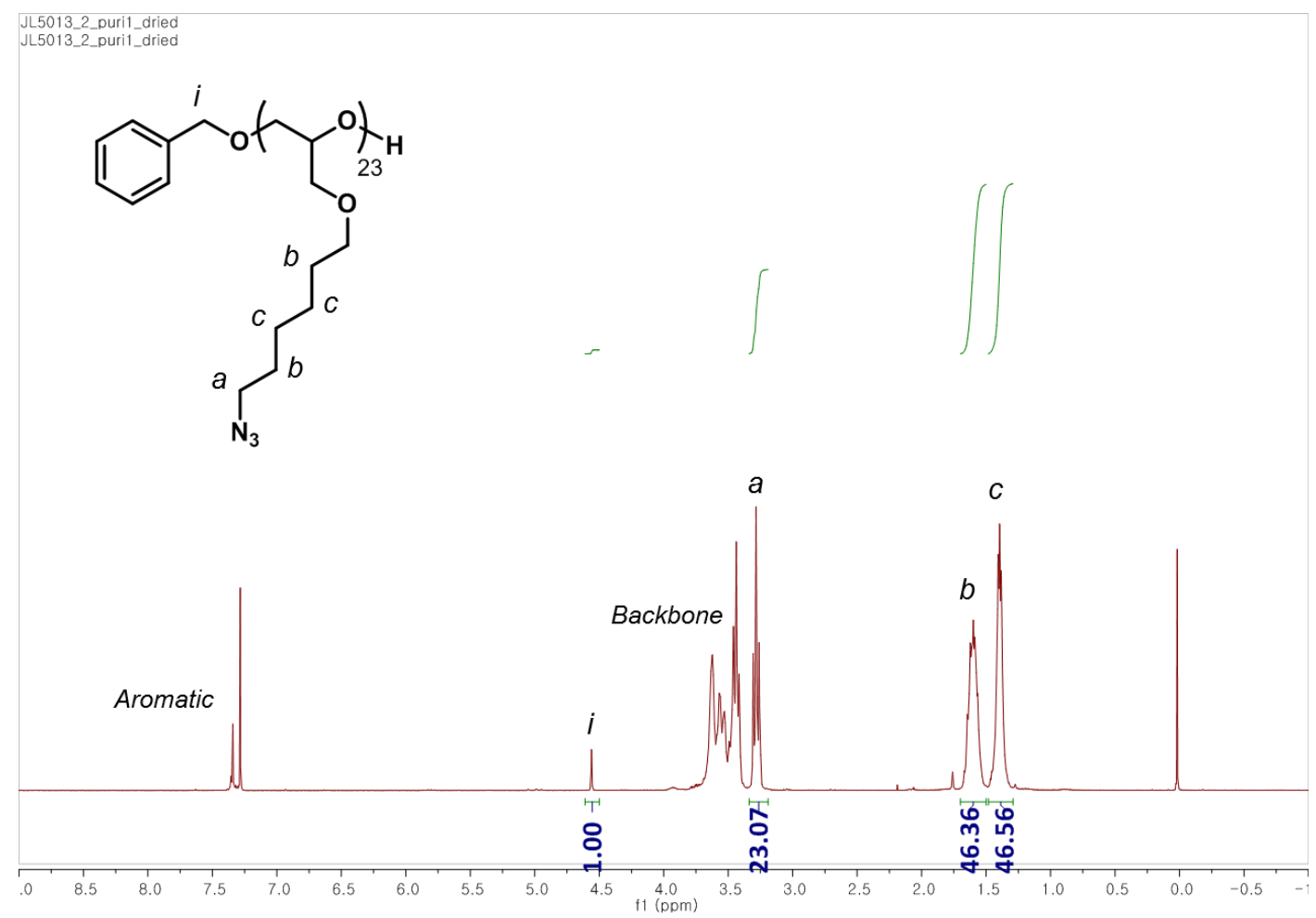

Figure S1. Representative ${ }^{1} \mathrm{H}$ NMR spectrum of $\mathrm{P}(\mathrm{AHGE})(\mathbf{H 2})$ in $\mathrm{CDCl}_{3}$.

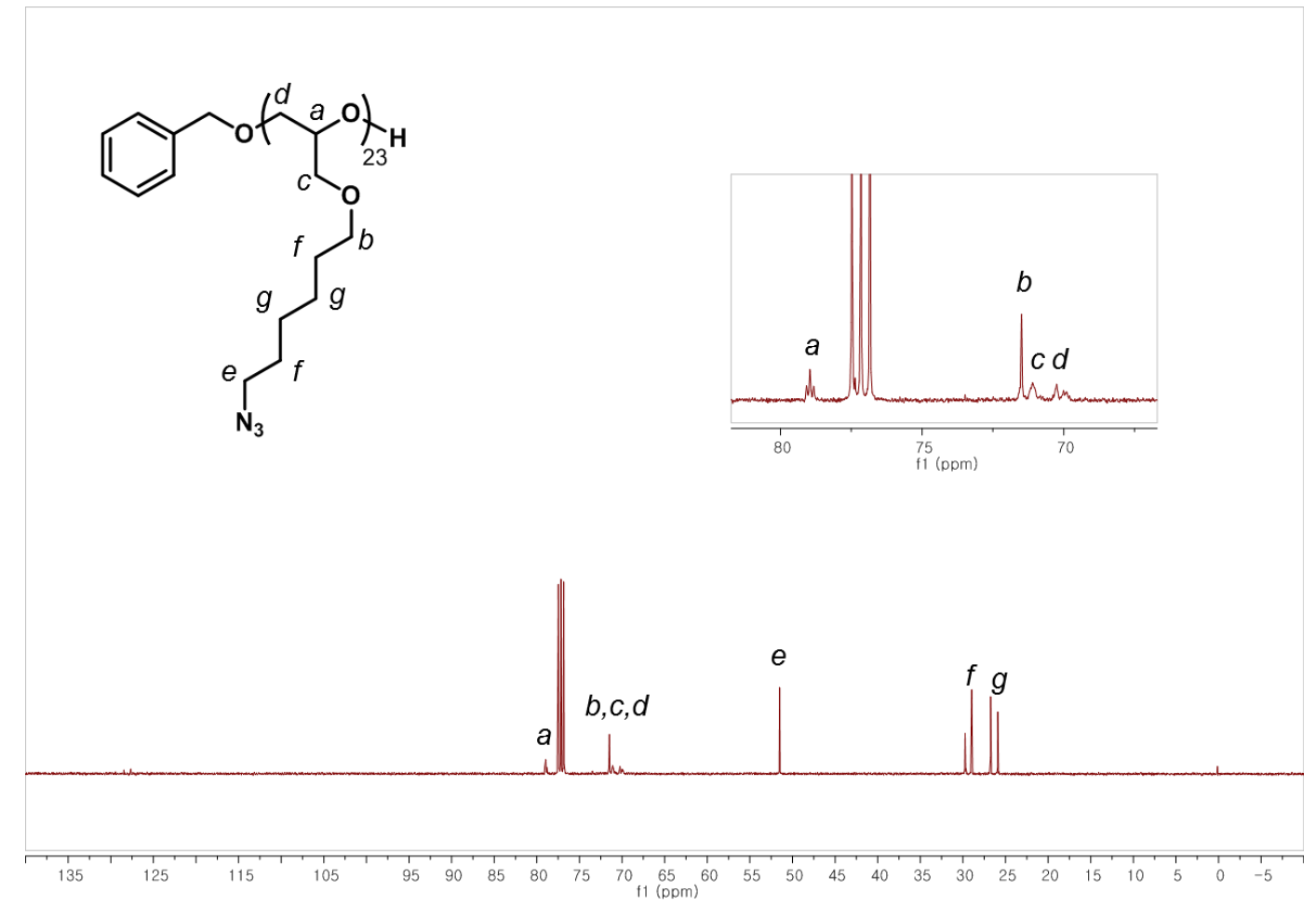

Figure S2. Representative ${ }^{13} \mathrm{C}$ NMR spectrum of $\mathrm{P}(\mathrm{AHGE})(\mathbf{H 2})$ in $\mathrm{CDCl}_{3}$. 


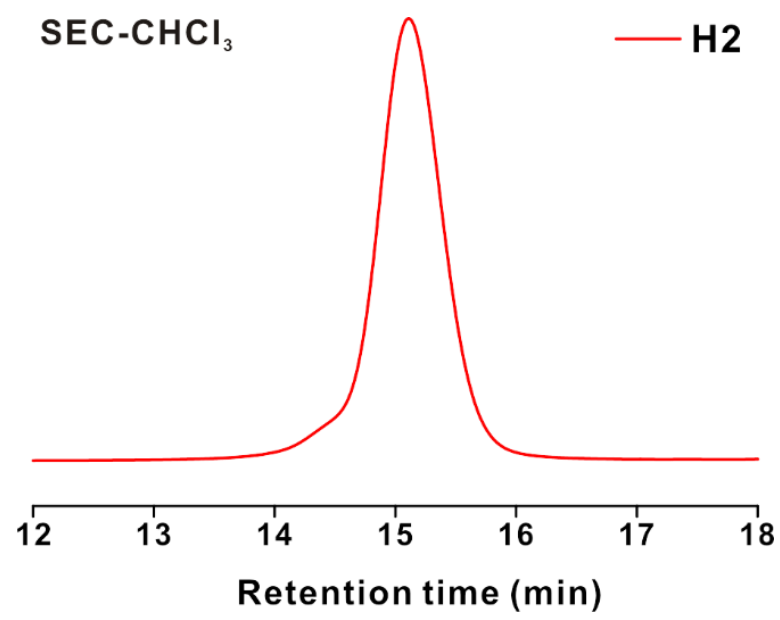

Figure S3. Representative SEC trace of $\mathrm{P}(\mathrm{AHGE})$ (H2).

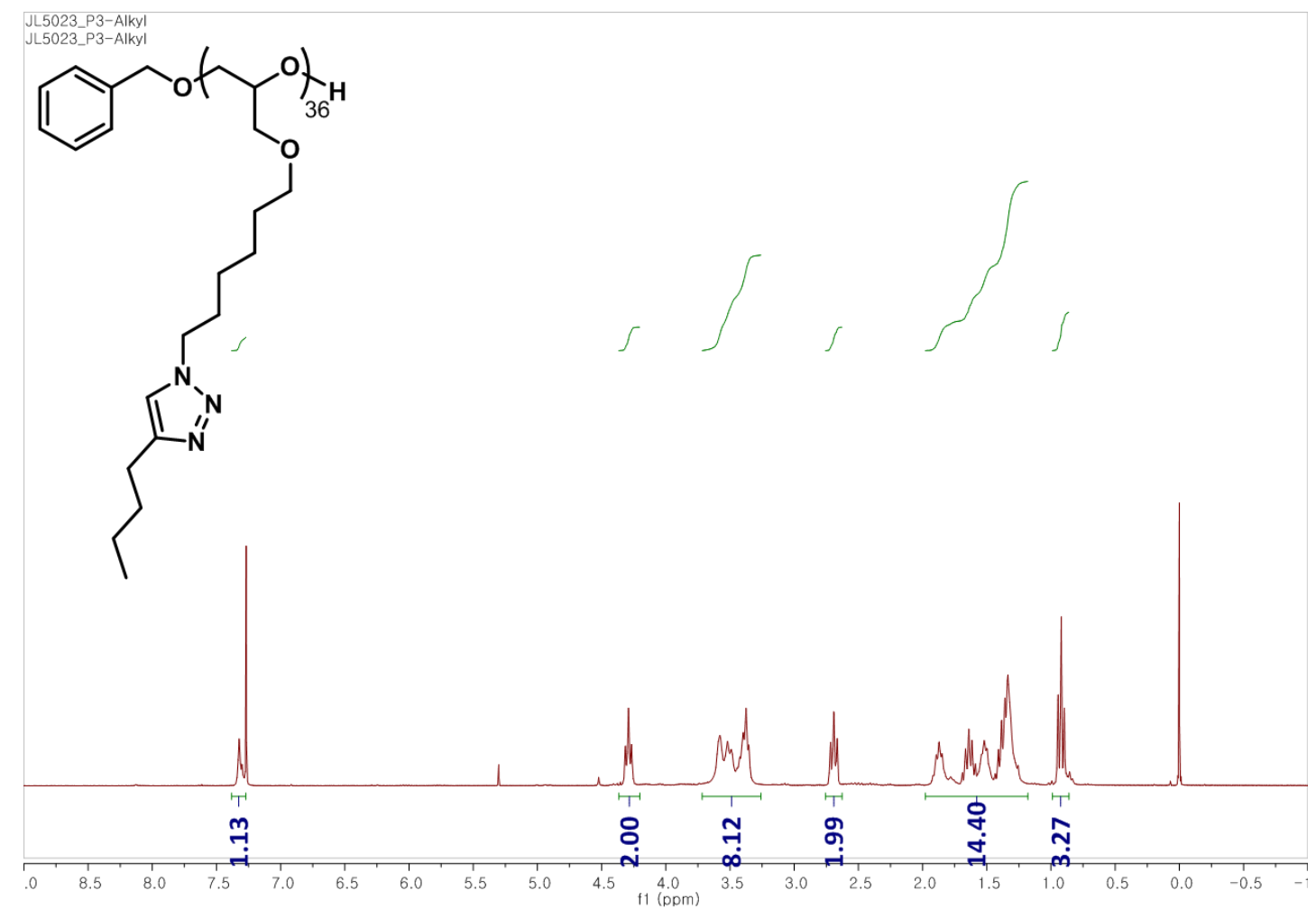

Figure S4. ${ }^{1} \mathrm{H}$ NMR spectrum of $\mathbf{H 3 a}$ in $\mathrm{CDCl}_{3}$. 


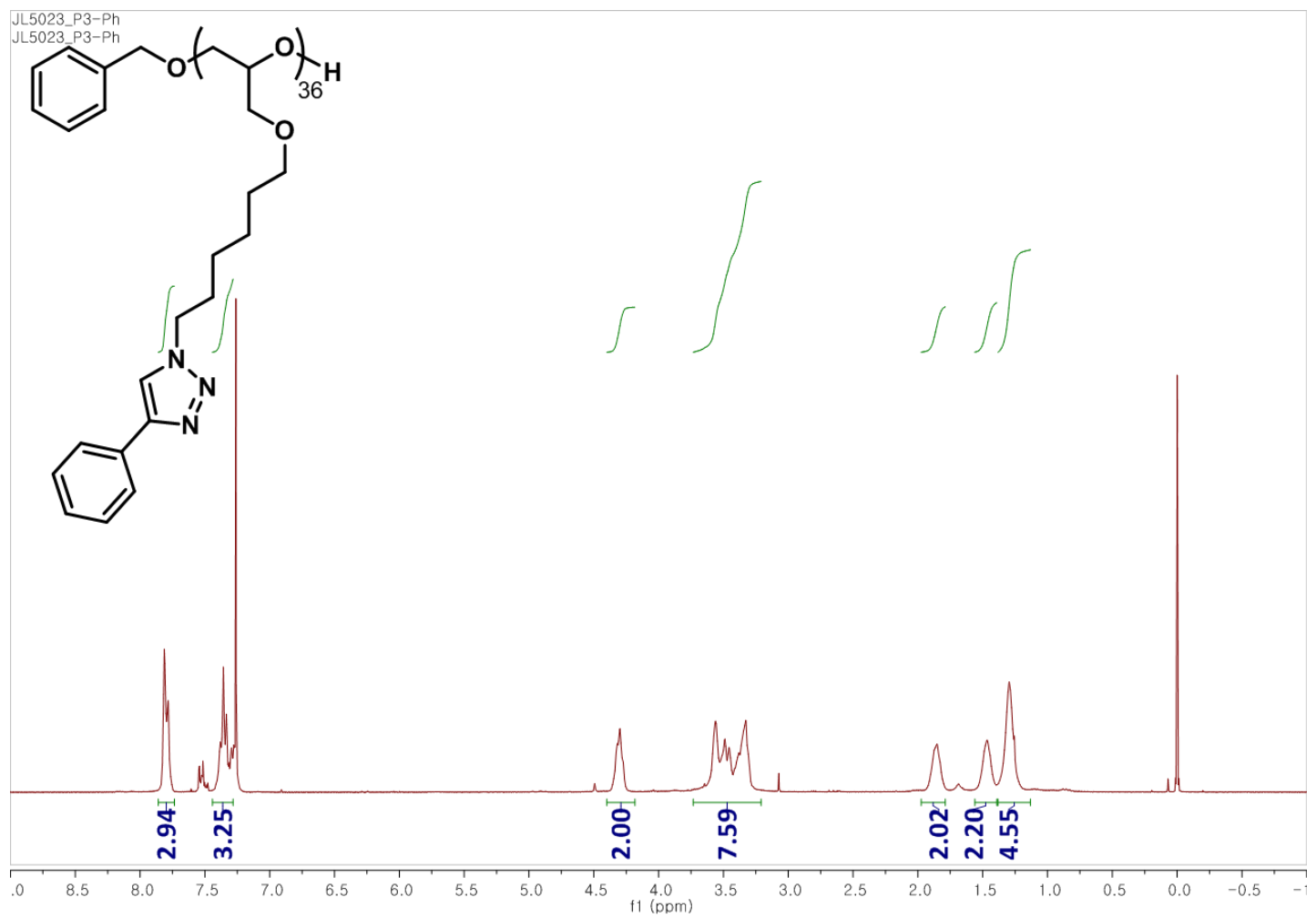

Figure S5. ${ }^{1} \mathrm{H}$ NMR spectrum of $\mathbf{H 3 b}$ in $\mathrm{CDCl}_{3}$.

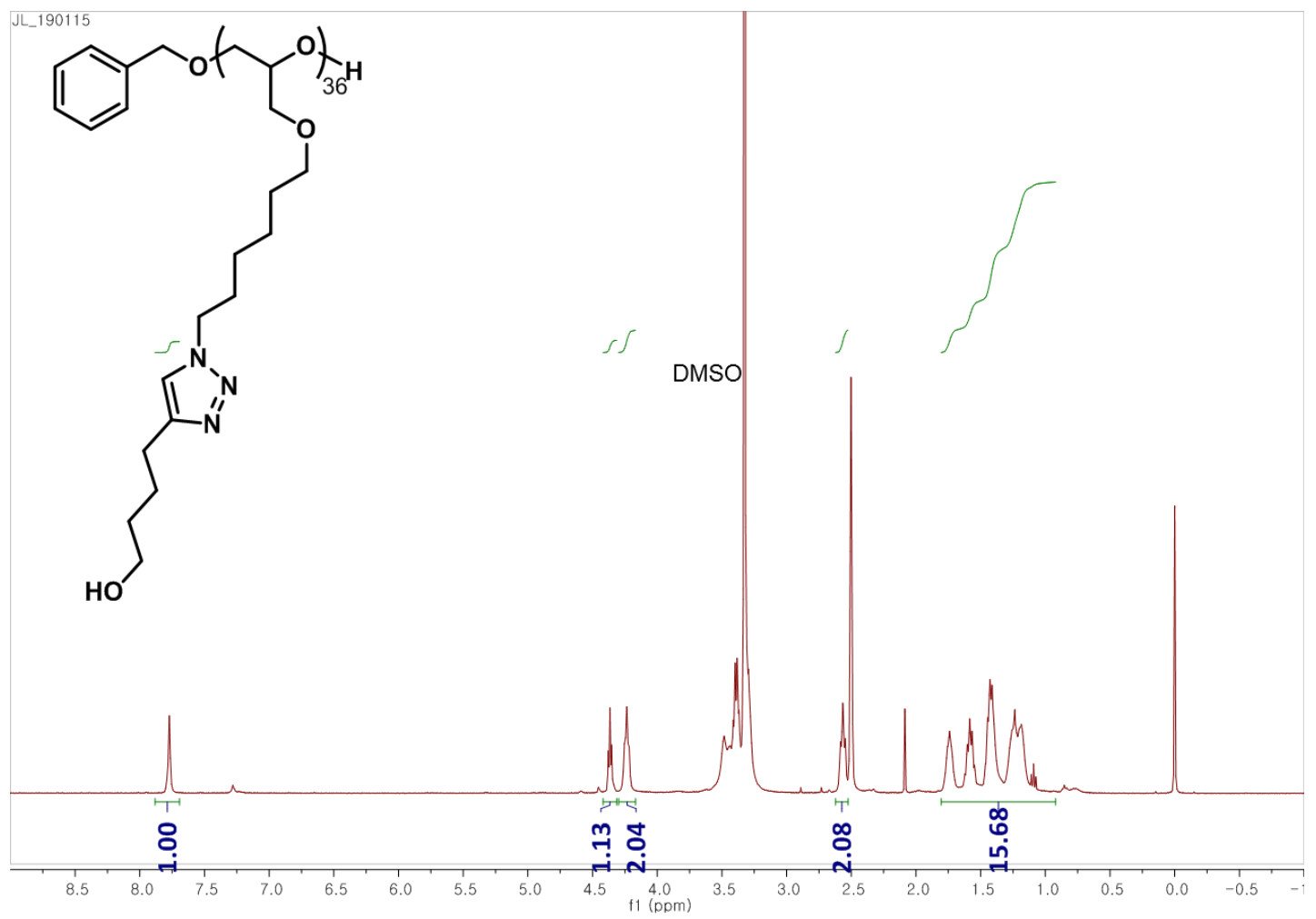

Figure S6. ${ }^{1} \mathrm{H}$ NMR spectrum of $\mathbf{H 3 c}$ in DMSO- $d_{6}$. 


\section{Polymerization of Glycidyl Azide}<smiles>OCc1ccccc1</smiles>

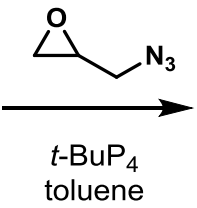<smiles>CC(CN)OC(C)COCc1ccccc1</smiles>

Glycidyl azide (GA) was prepared according to literature procedure. ${ }^{\mathrm{S} 1}$

A procedure for the polymerization of $\mathrm{GA}: t-\mathrm{BuP}_{4}(0.8 \mathrm{M}$ in hexane, $210 \mu \mathrm{L})$ was added to a solution of benzyl alcohol $(17.58 \mu \mathrm{L}, 0.17 \mathrm{mmol})$ in toluene $(1.0 \mathrm{~mL})$ and stirred for $30 \mathrm{~min}$. GA (500 mg, $5.0 \mathrm{mmol}$ ) was then slowly added to the solution to initiate the polymerization. The reaction mixture was stirred at room temperature for $18 \mathrm{~h}$, and then it was quenched with an excess amount of benzoic acid. The mixture was passed through a basic alumina pad using THF and characterized by ${ }^{1} \mathrm{H}$ NMR.

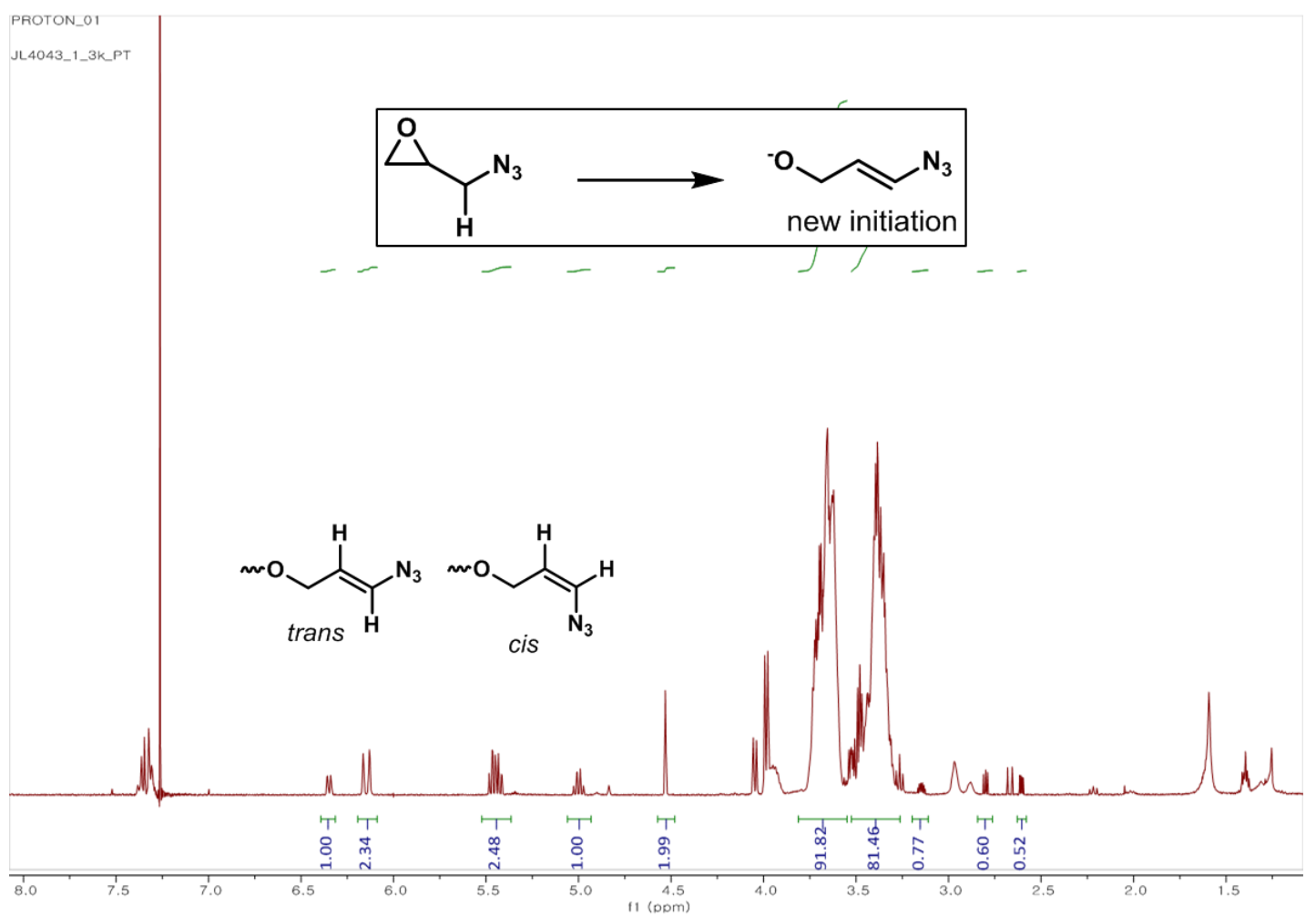

Figure S7. ${ }^{1} \mathrm{H}$ NMR spectrum of the polymerization of GA. The presence of olefinic protons around $5.0-6.5 \mathrm{ppm}$ indicates that undesired elimination reaction of GA occurred. 


\section{Synthesis and Characterization of a Series of Azidoalkyl Glycidyl Ethers}

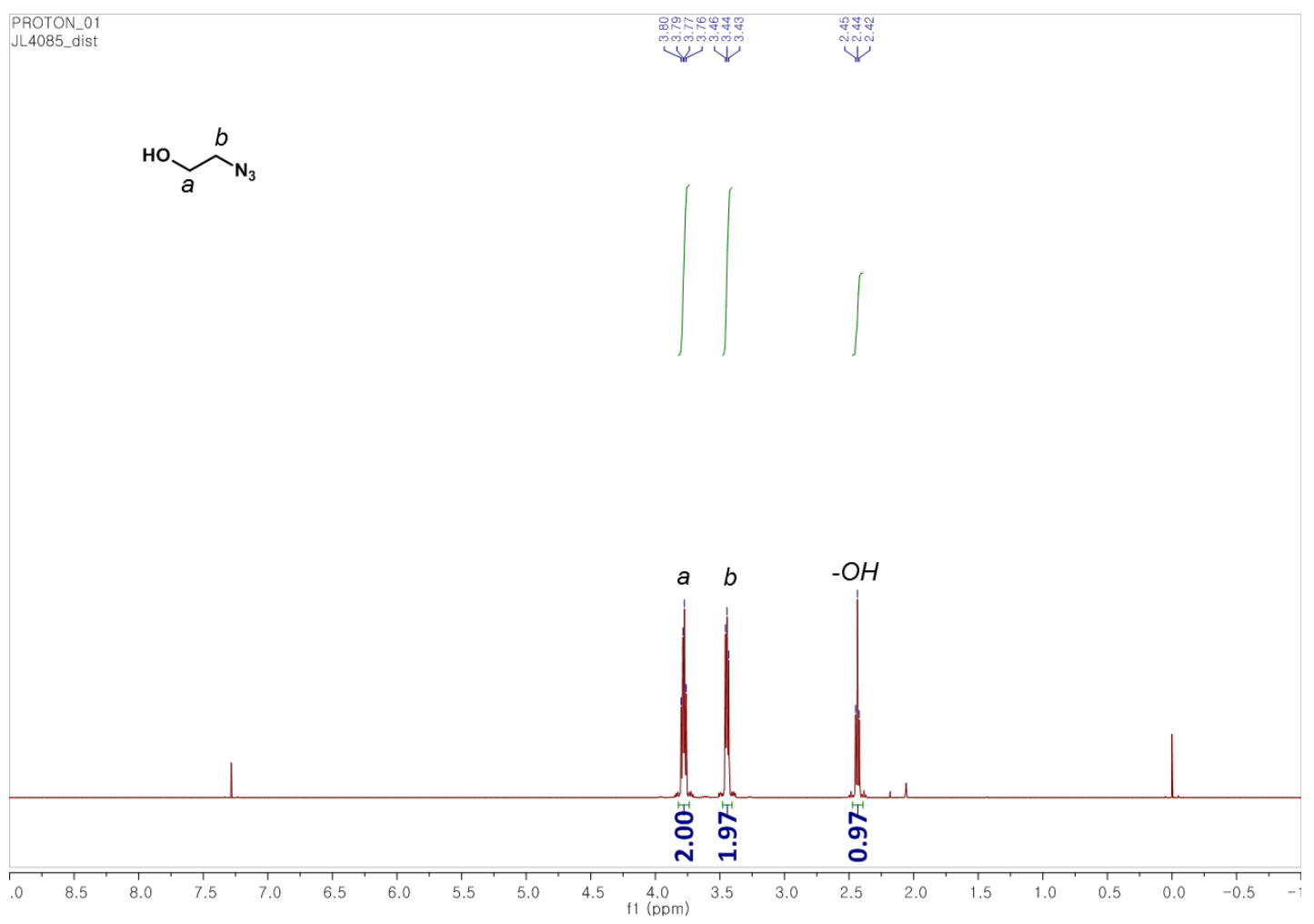

Figure S8. ${ }^{1} \mathrm{H}$ NMR spectrum of 2-azido-1-ethanol (1b) (400 MHz, $\left.\mathrm{CDCl}_{3}, 298 \mathrm{~K}\right)$

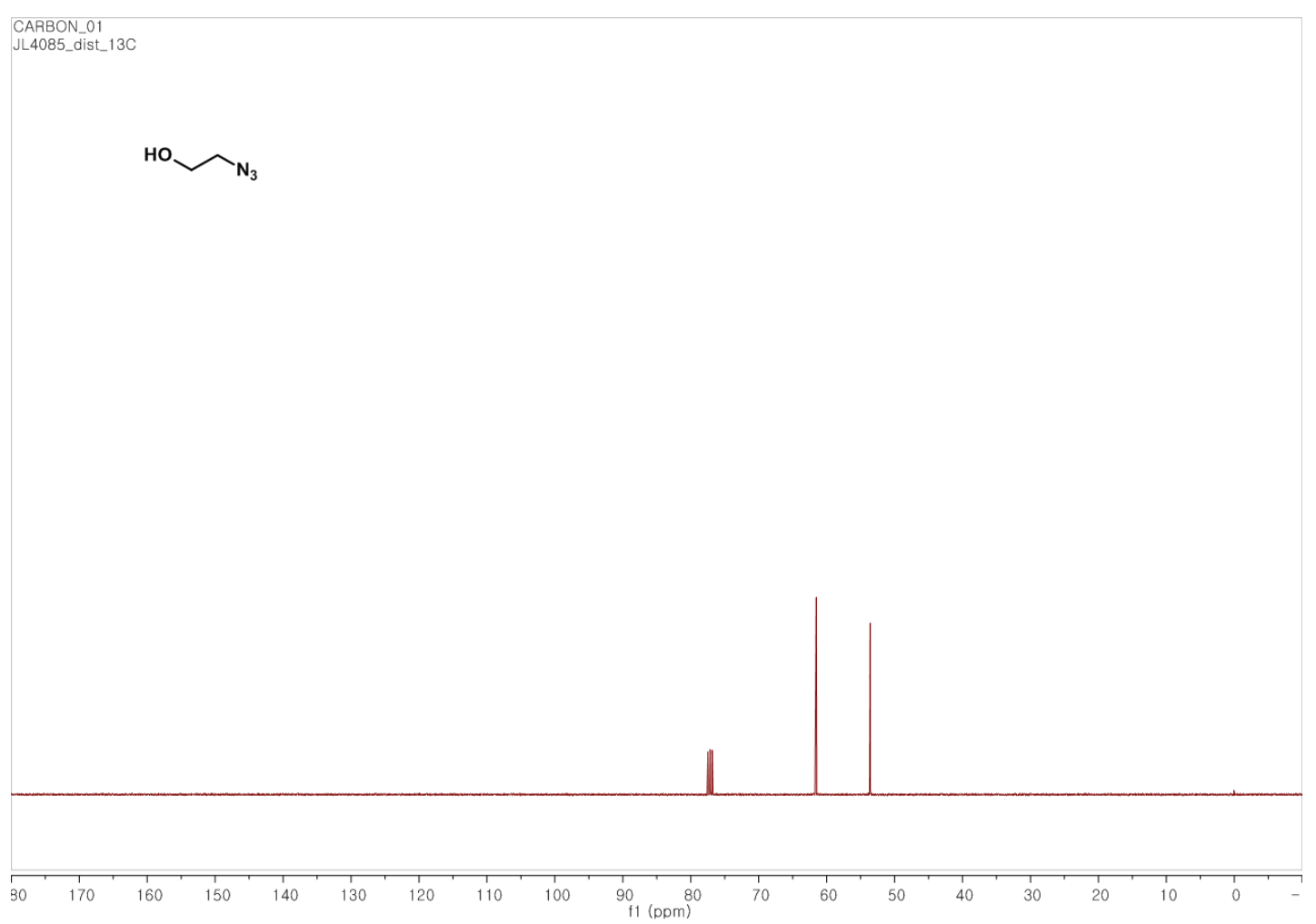

Figure S9. ${ }^{13} \mathrm{C}$ NMR spectrum of 2-azido-1-ethanol (1b) (101 $\left.\mathrm{MHz}, \mathrm{CDCl}_{3}, 298 \mathrm{~K}\right)$ 


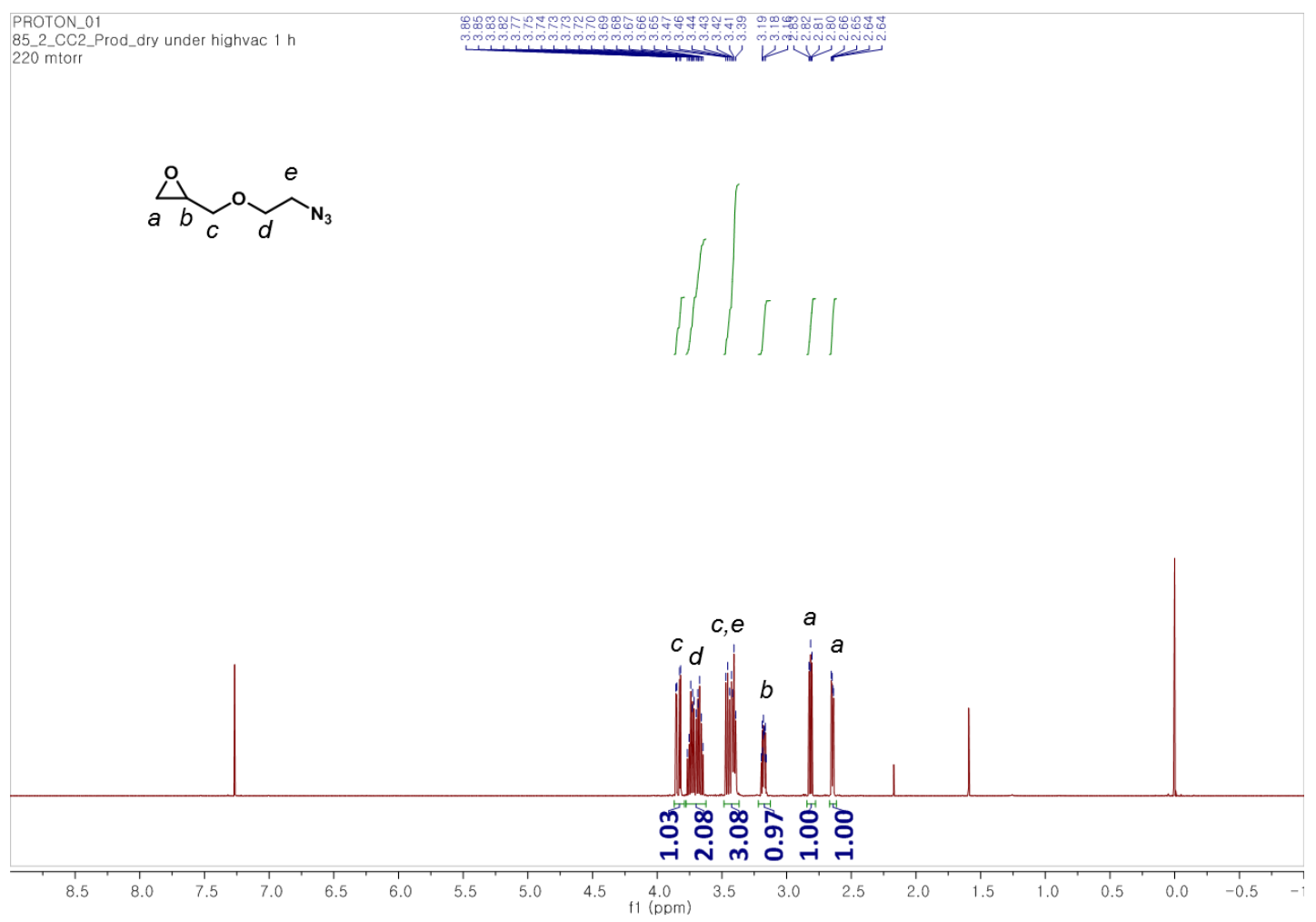

Figure S10. ${ }^{1} \mathrm{H}$ NMR spectrum of AEGE (400 MHz, $\mathrm{CDCl}_{3}, 298 \mathrm{~K}$ ).

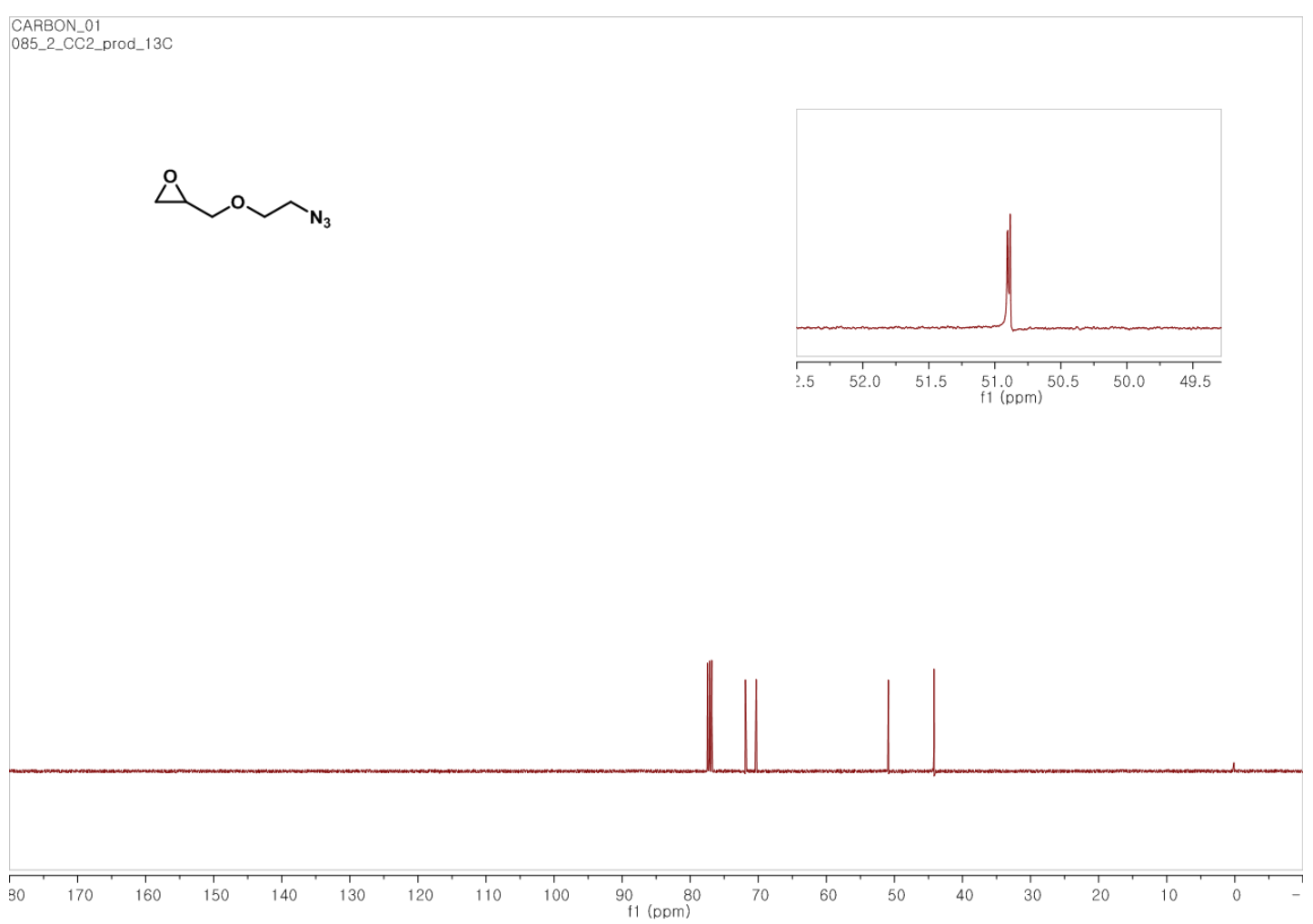

Figure S11. ${ }^{13} \mathrm{C}$ NMR spectrum of AEGE (101 $\left.\mathrm{MHz}, \mathrm{CDCl}_{3}, 298 \mathrm{~K}\right)$. 


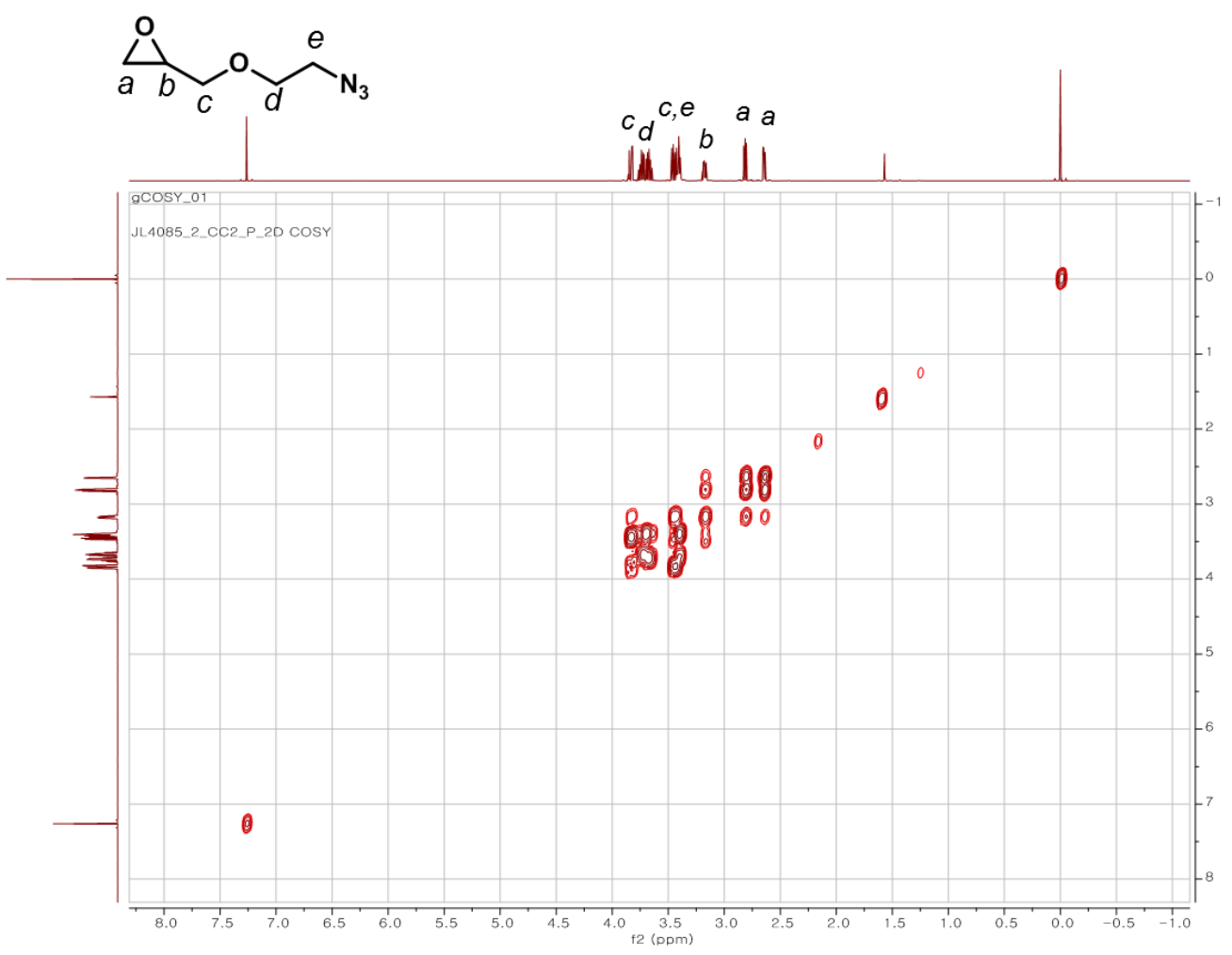

Figure S12. ${ }^{1} \mathrm{H}-{ }^{1} \mathrm{H}$ COSY NMR spectrum of AEGE in $\mathrm{CDCl}_{3}$.

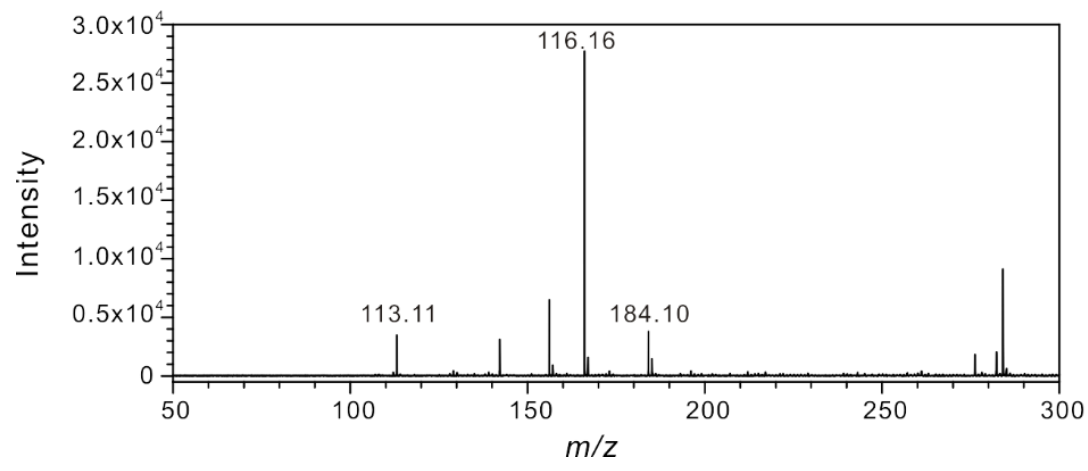

Figure S13. ESI-MS spectrum of AEGE. 


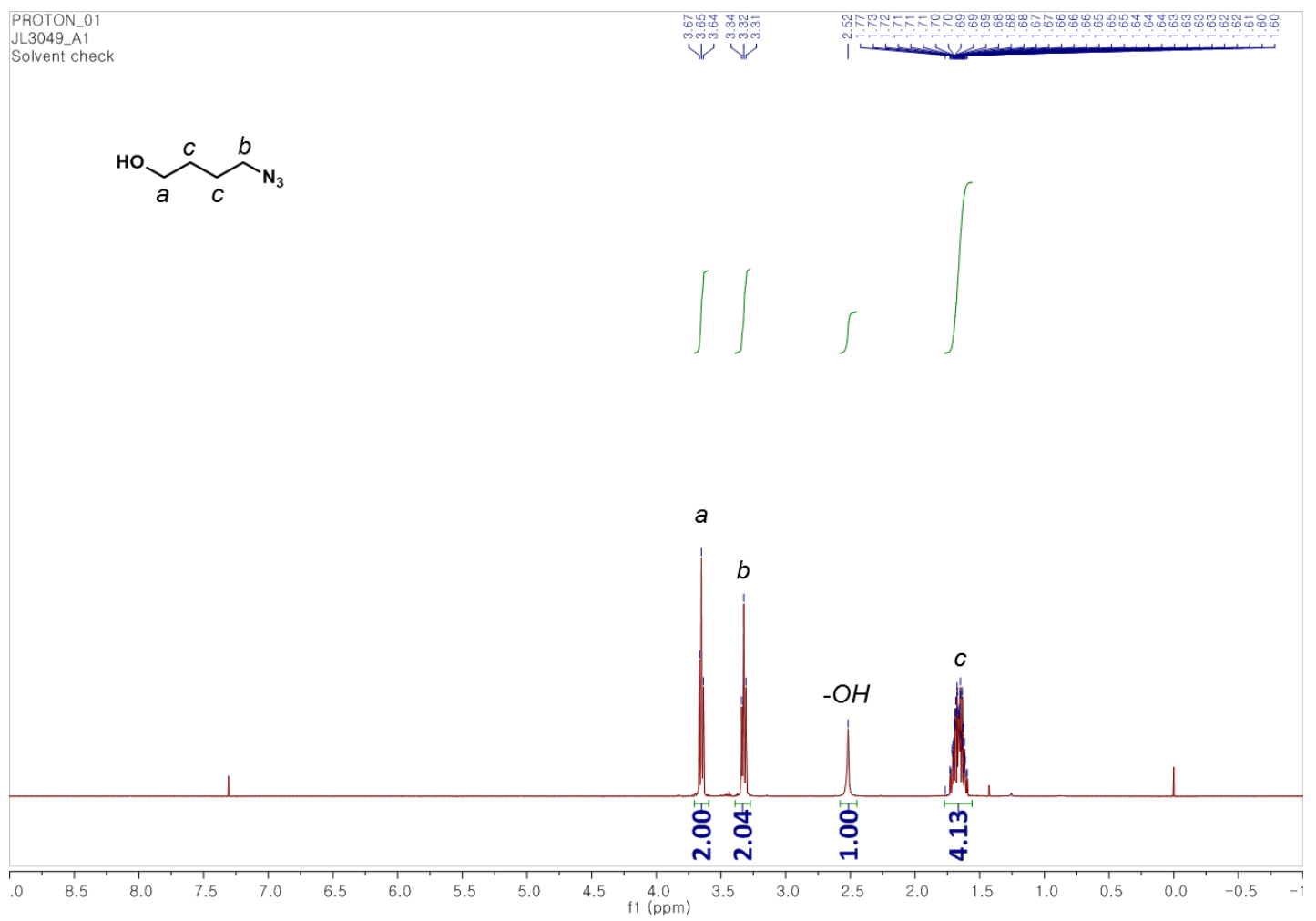

Figure S14. ${ }^{1} \mathrm{H}$ NMR spectrum of 4-azido-1-butanol (2b) $\left(400 \mathrm{MHz}, \mathrm{CDCl}_{3}, 298 \mathrm{~K}\right)$.

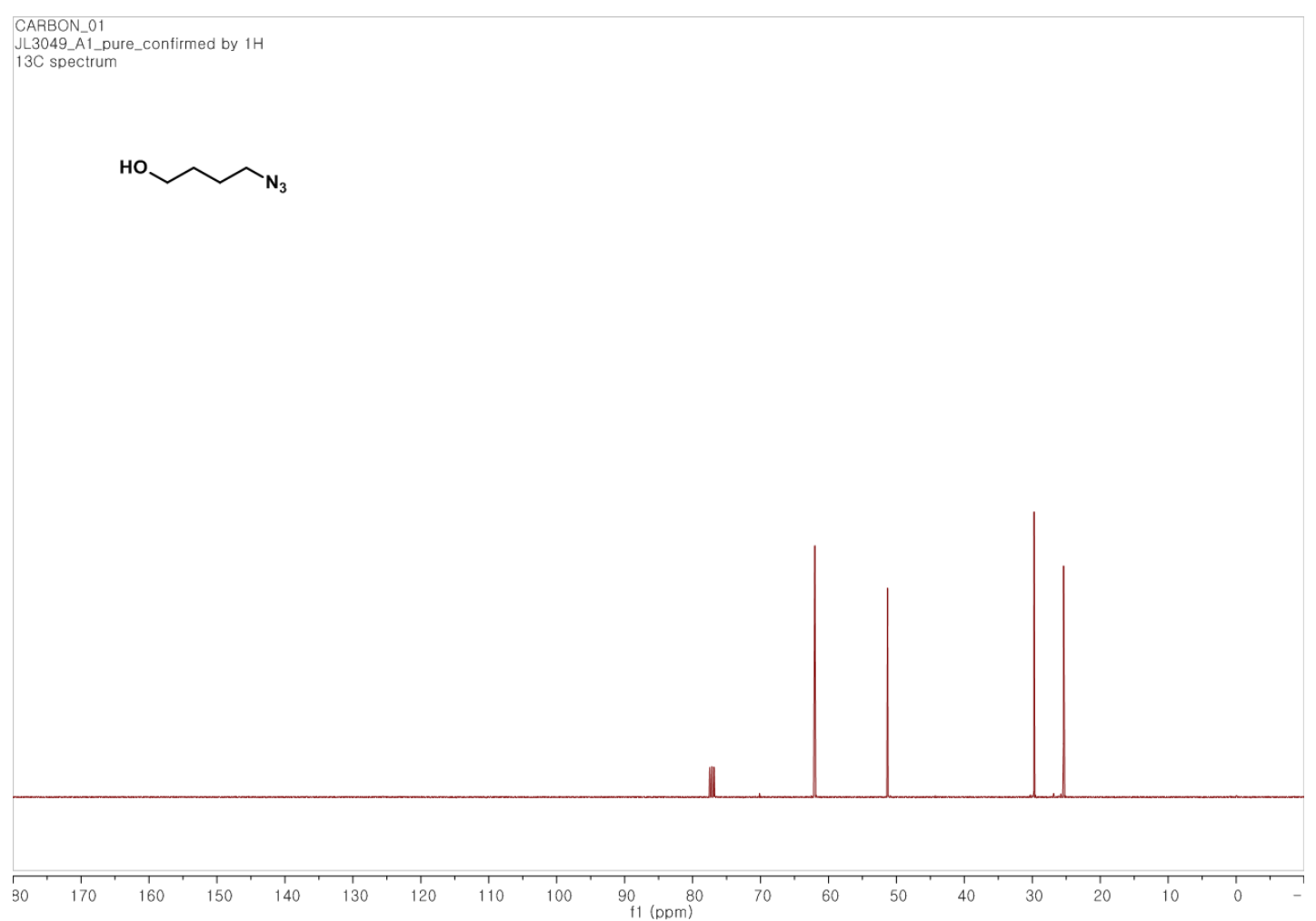

Figure S15. ${ }^{13} \mathrm{C}$ NMR spectrum of 4-azido-1-butanol (2b) (101 MHz, $\left.\mathrm{CDCl}_{3}, 298 \mathrm{~K}\right)$. 


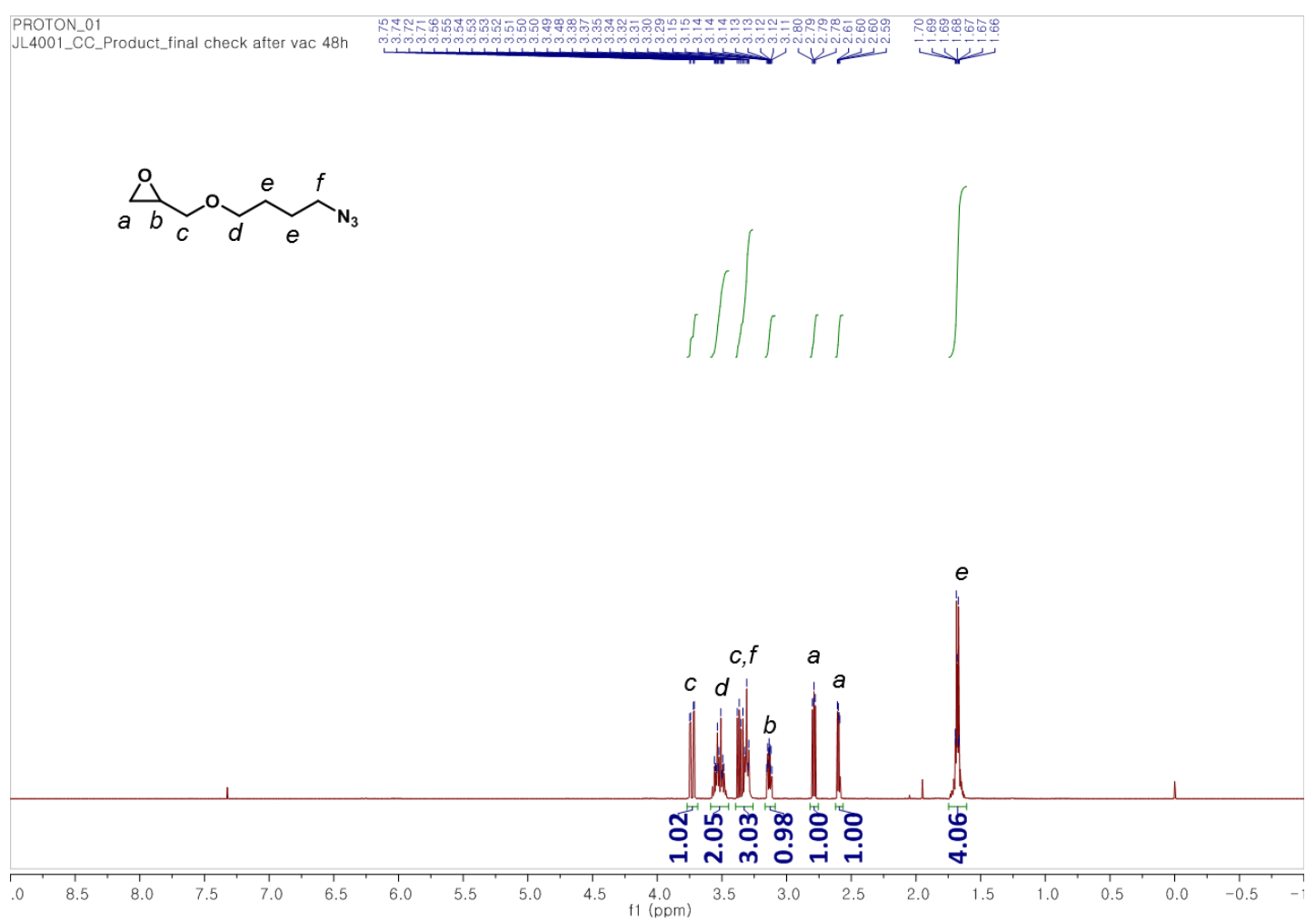

Figure S16. ${ }^{1} \mathrm{H}$ NMR spectrum of ABGE (400 MHz, $\mathrm{CDCl}_{3}, 298 \mathrm{~K}$ ).

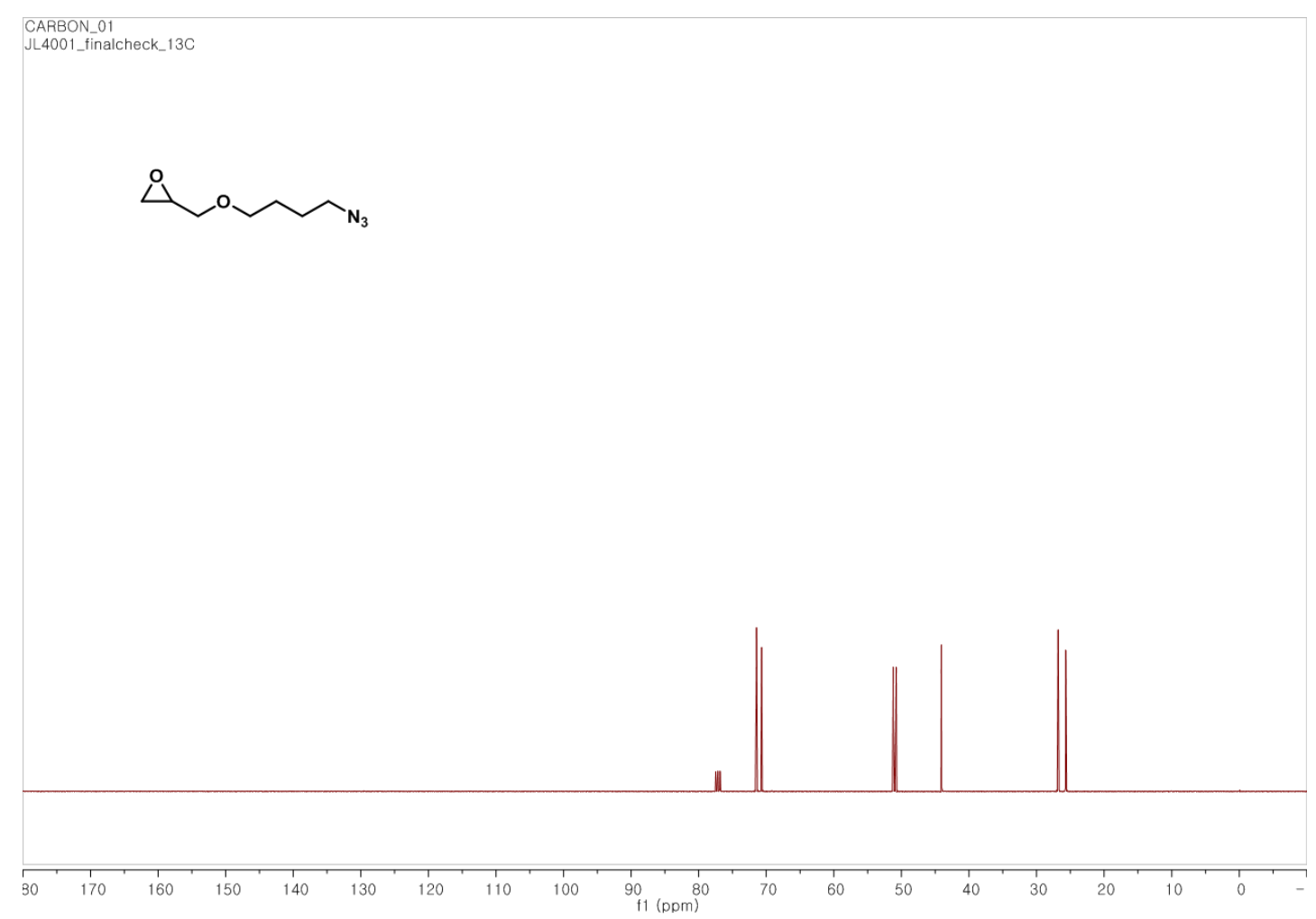

Figure S17. ${ }^{13} \mathrm{C}$ NMR spectrum of ABGE (101 MHz, $\left.\mathrm{CDCl}_{3}, 298 \mathrm{~K}\right)$. 


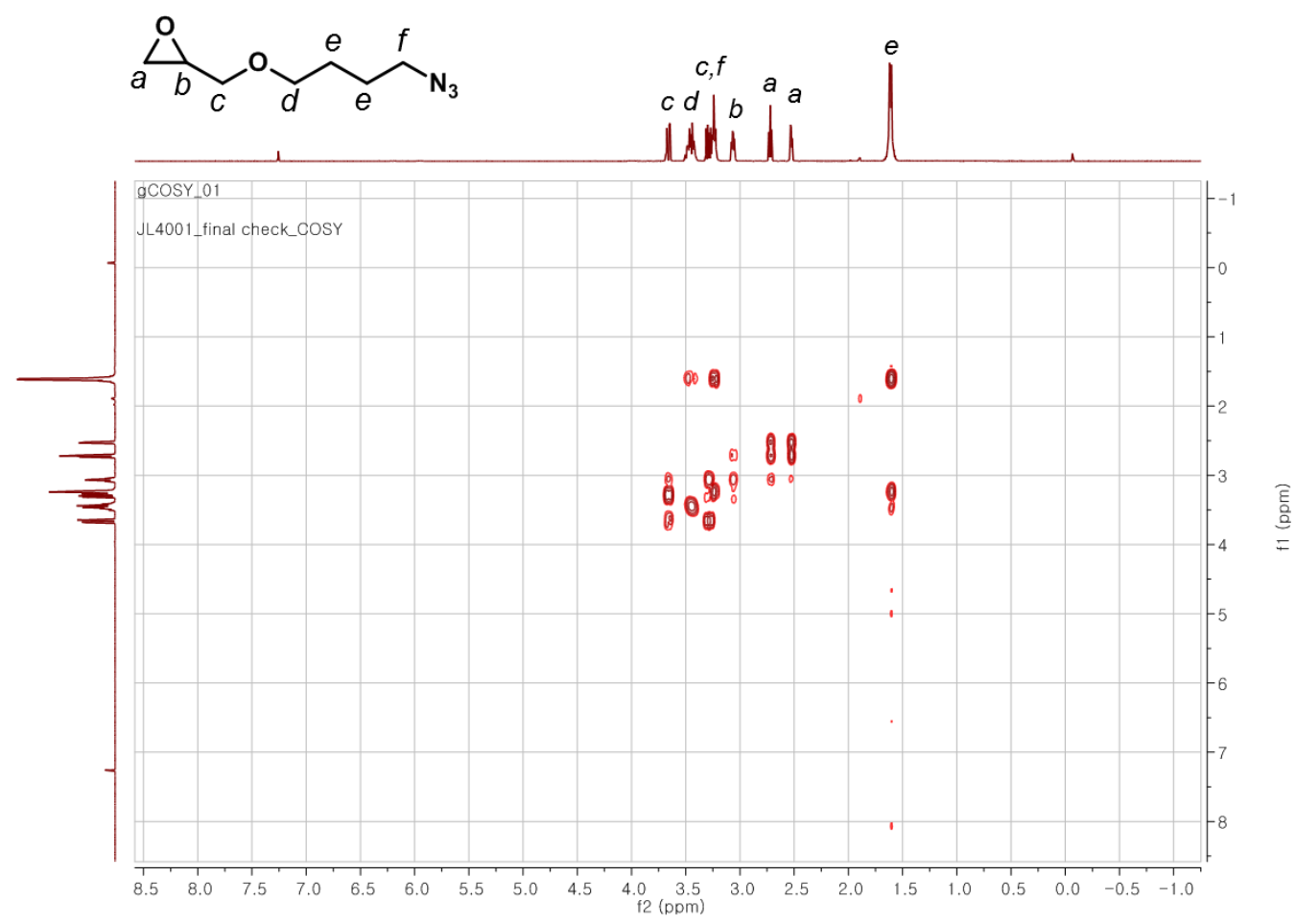

Figure S18. ${ }^{1} \mathrm{H}^{-1} \mathrm{H}$ COSY NMR spectrum of ABGE in $\mathrm{CDCl}_{3}$.

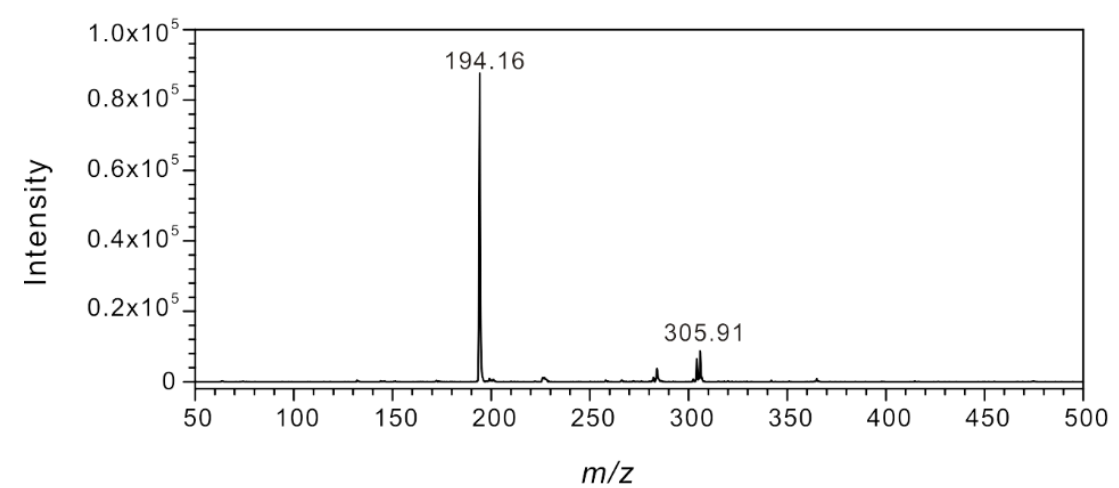

Figure S19. ESI-MS spectrum of ABGE. 


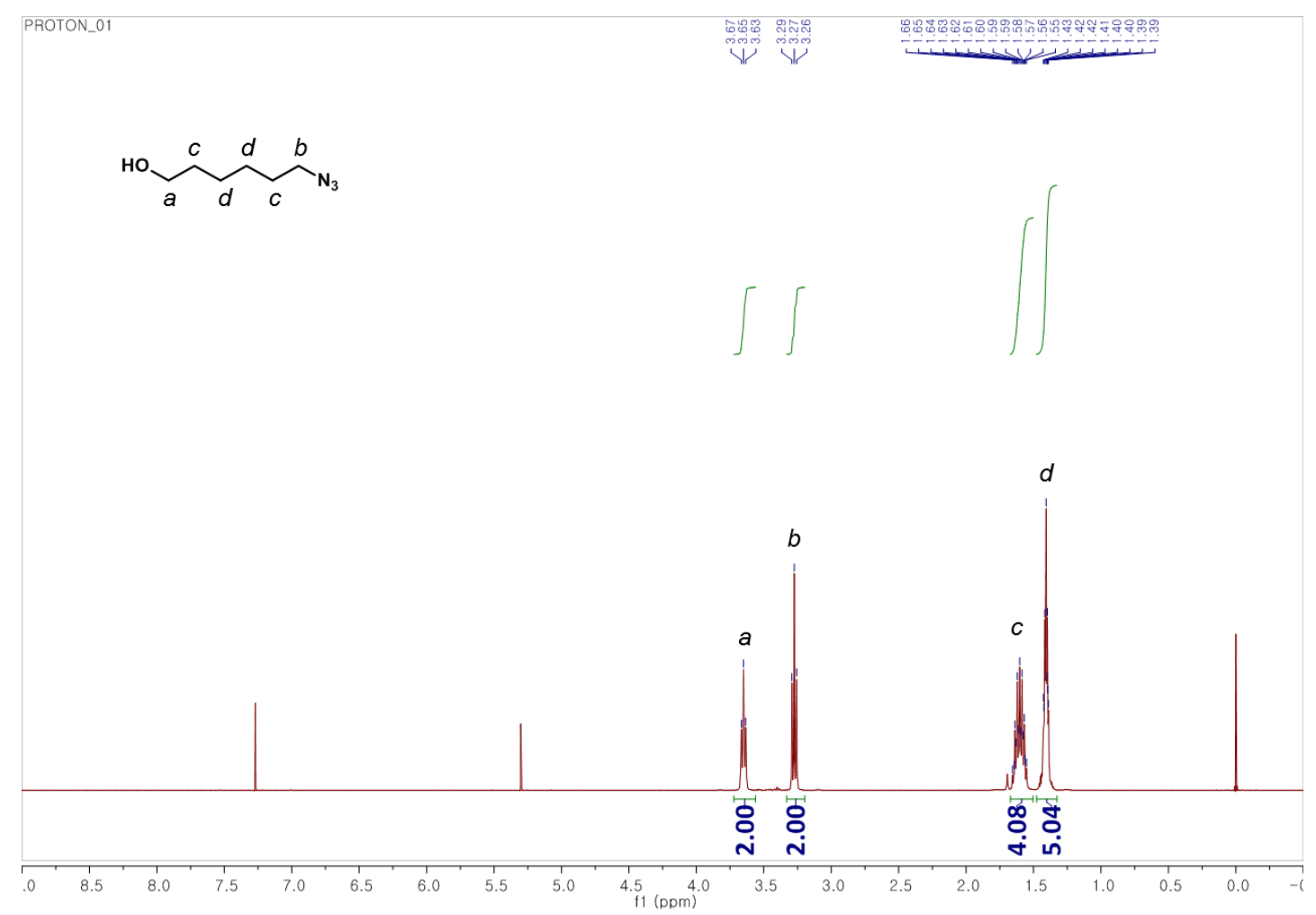

Figure S20. ${ }^{1} \mathrm{H}$ NMR spectrum of 6-azido-1-hexanol (3b) (400 MHz, $\left.\mathrm{CDCl}_{3}, 298 \mathrm{~K}\right)$.

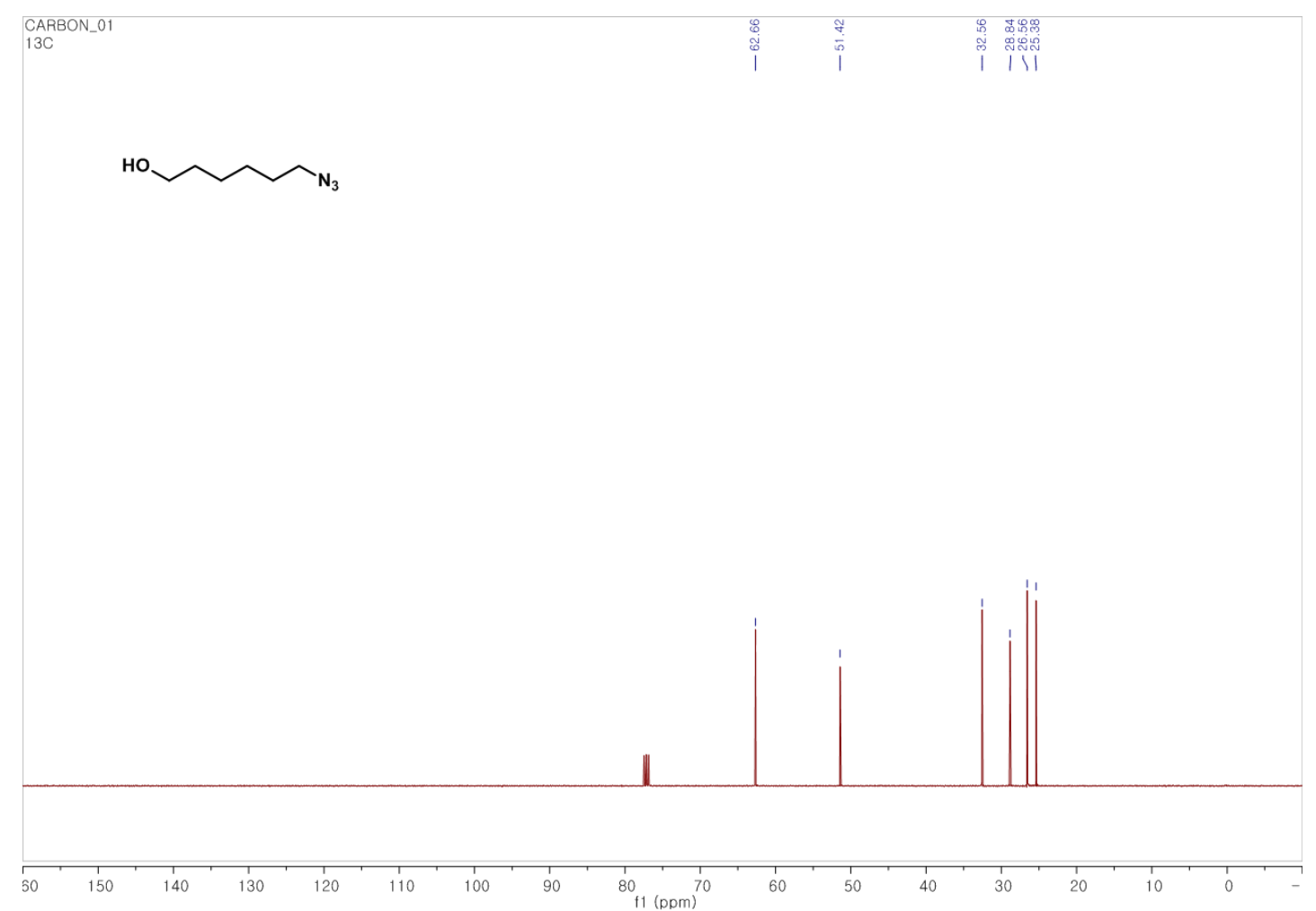

Figure S21. ${ }^{13} \mathrm{C}$ NMR spectrum of 6-azido-1-hexanol (3b) (101 MHz, $\left.\mathrm{CDCl}_{3}, 298 \mathrm{~K}\right)$. 


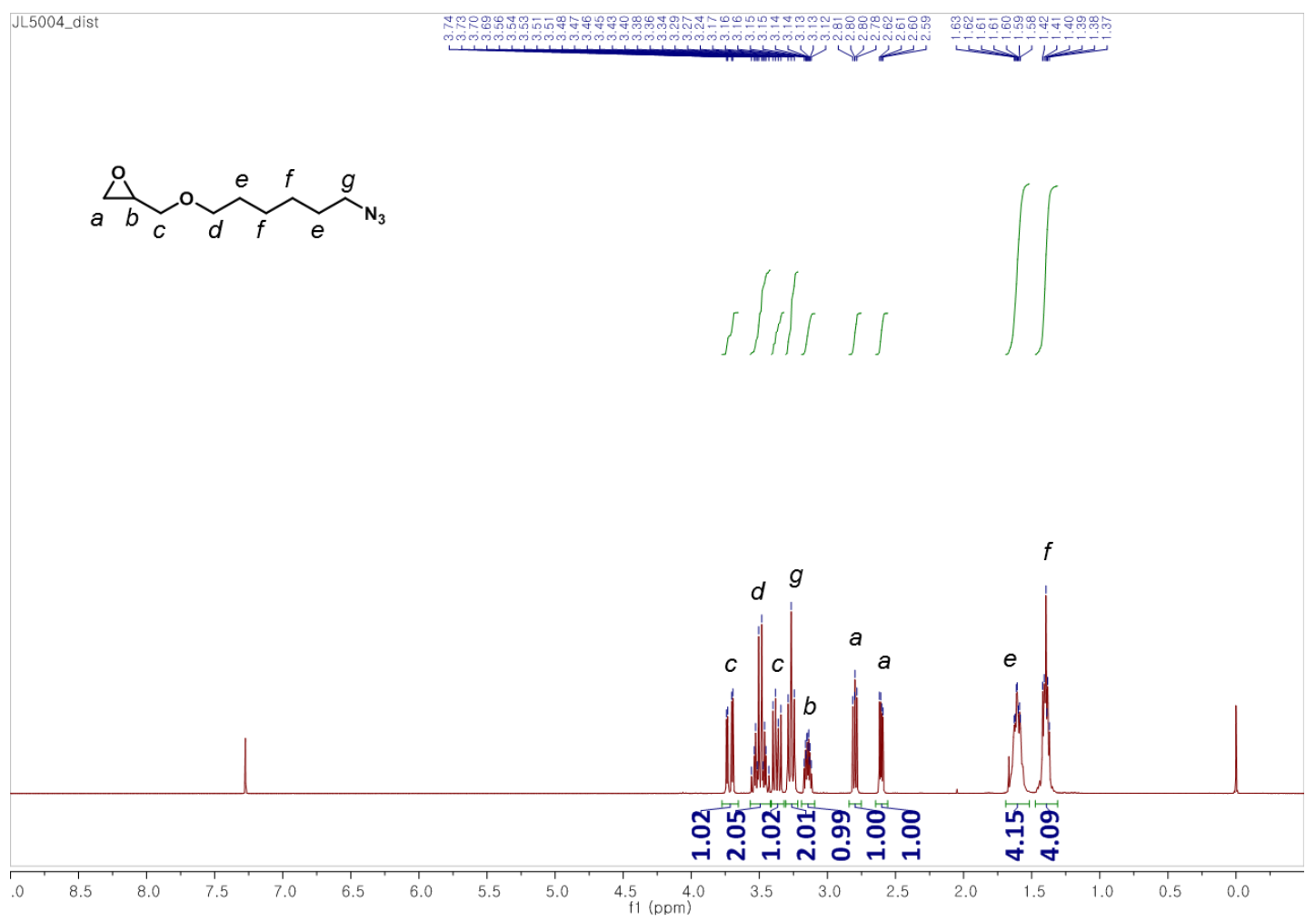

Figure S22. ${ }^{1} \mathrm{H}$ NMR spectrum of AHGE (400 MHz, $\left.\mathrm{CDCl}_{3}, 298 \mathrm{~K}\right)$.

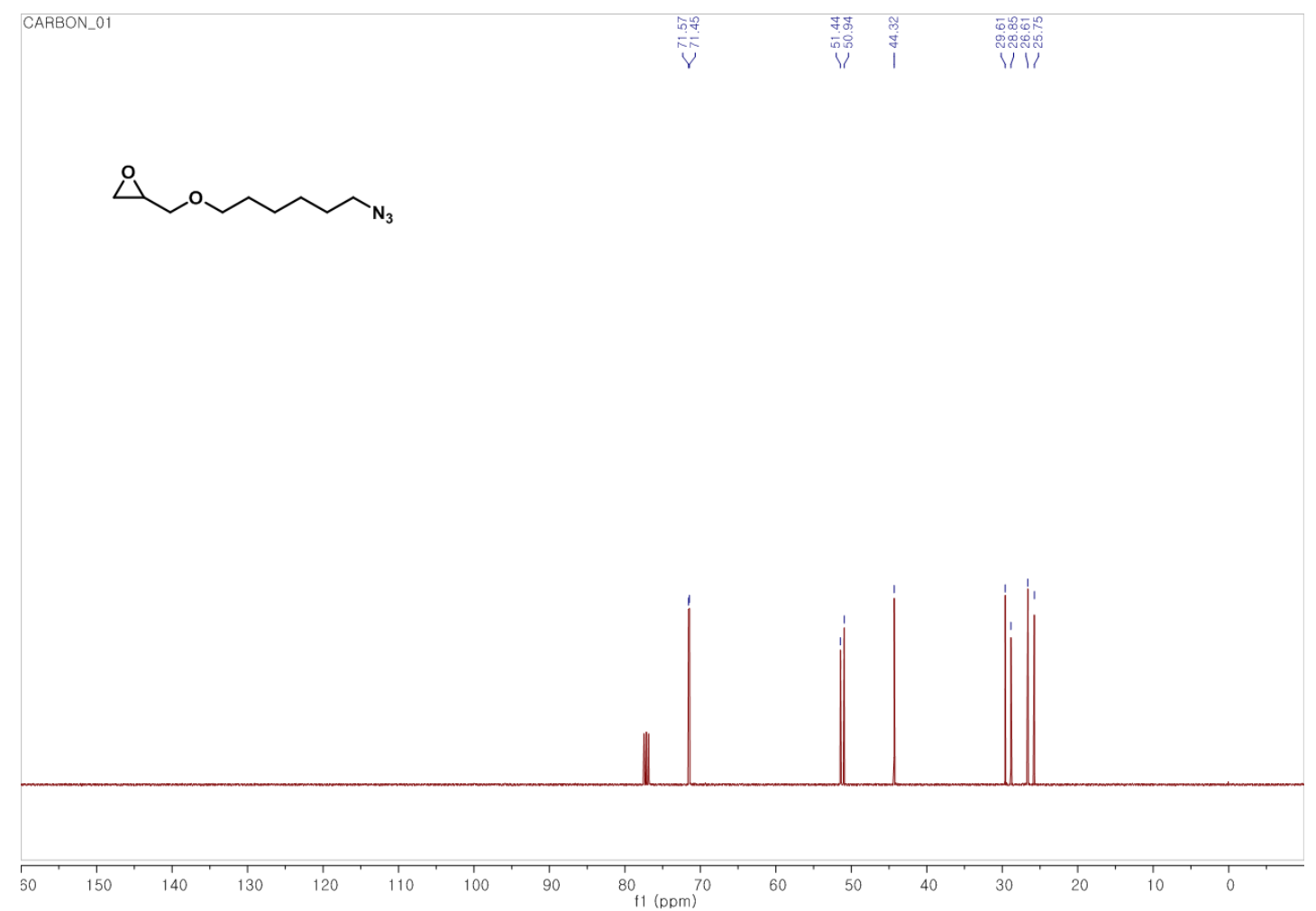

Figure S23. ${ }^{13} \mathrm{C}$ NMR spectrum of AHGE (101 $\mathrm{MHz}, \mathrm{CDCl}_{3}, 298 \mathrm{~K}$ ). 


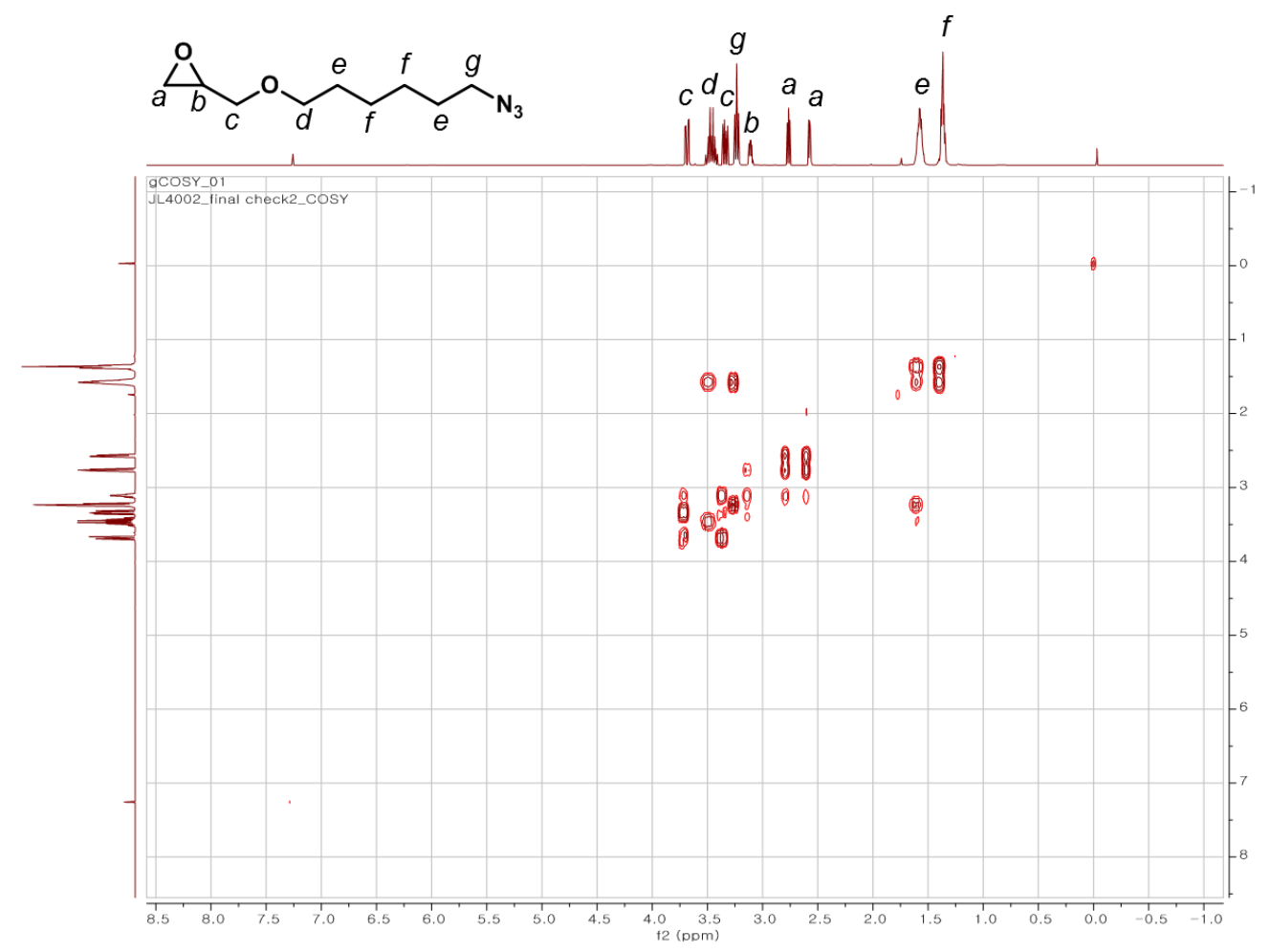

Figure S24. ${ }^{1} \mathrm{H}-{ }^{1} \mathrm{H}$ COSY NMR spectrum of AHGE in $\mathrm{CDCl}_{3}$.

\section{Removal of $t$-BuP 4}

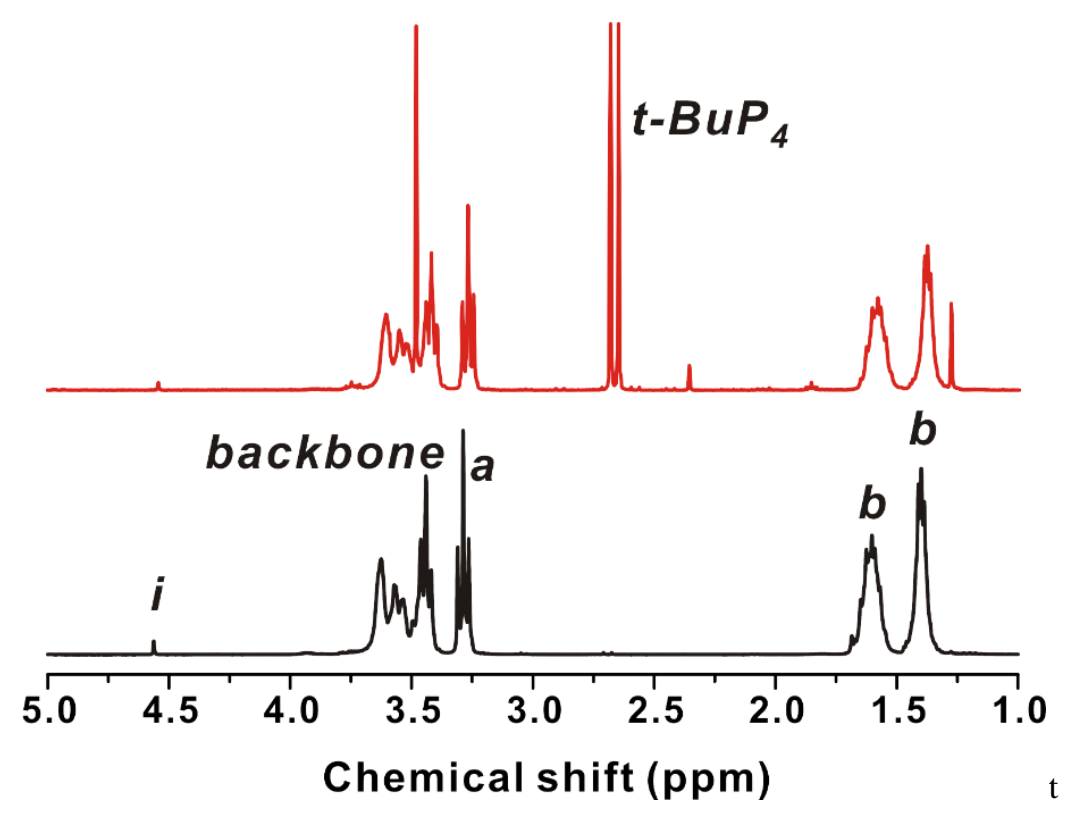

Figure S25. ${ }^{1} \mathrm{H}$ NMR spectrum of $\mathrm{P}(\mathrm{AHGE})$ (H4) before (top) and after purification (bottom) in $\mathrm{CDCl}_{3}$. 
FT-IR Spectra of AHGE and P(AHGE)

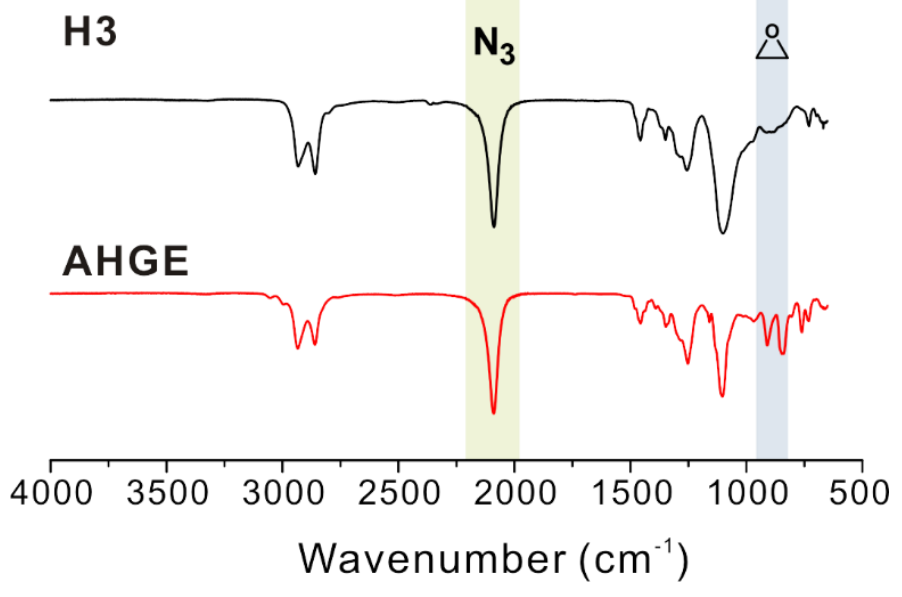

Figure S26. FT-IR spectra of H3 and AHGE monomer. 
Azide Stability Test

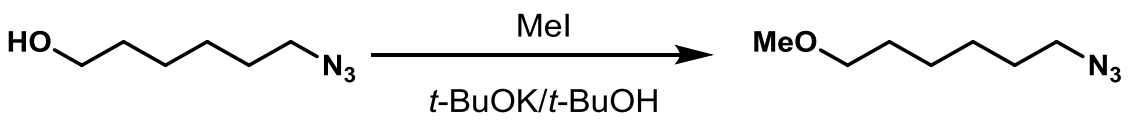

Preparation of 1-azido-6-methoxyhexane is described as follows. To a solution of potassium tert-butoxide $(0.94 \mathrm{~g}, 8.38 \mathrm{mmol})$ dissolved in $30.0 \mathrm{~mL}$ of tert-butanol was added 6-azido-1hexanol $(1.0 \mathrm{~g}, 6.98 \mathrm{mmol})$. After the mixture was stirred for $30 \mathrm{~min}$, methyl iodide $(1.19 \mathrm{~g}$, $8.38 \mathrm{mmol}$ ) was slowly added. The reaction was maintained for $24 \mathrm{~h}$ at room temperature, then the mixture was quenched by water and the aqueous phase was extracted with dichloromethane. The organic layers were washed with brine, dried over $\mathrm{Na}_{2} \mathrm{SO}_{4}$ and the solvent was evaporated. The crude liquid was purified by column chromatography (ethyl acetate/hexane 1:2) to yield $0.45 \mathrm{~g}(41 \%)$ of 1-azido-6-methoxyhexane. ${ }^{1} \mathrm{H}$ NMR (400 MHz, $\left.\mathrm{CDCl}_{3}\right): \delta 3.37$ (t, J = $6.5 \mathrm{~Hz}$, $2 \mathrm{H}), 3.33(\mathrm{~s}, 3 \mathrm{H}), 3.27(\mathrm{t}, \mathrm{J}=6.9 \mathrm{~Hz}, 2 \mathrm{H}), 1.66-1.52(\mathrm{~m}, 4 \mathrm{H}), 1.47-1.31(\mathrm{~m}, 4 \mathrm{H})$.

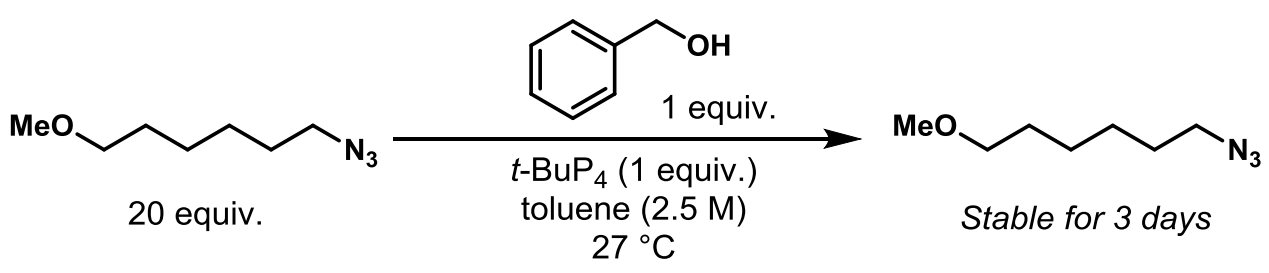

Procedure: In a $20 \mathrm{~mL}$ dried reaction vial, $t$ - $\mathrm{BuP}_{4}(40.0 \mu \mathrm{L}, 0.032 \mathrm{mmol})$ was added to a solution of benzyl alcohol (3.35 $\mu \mathrm{L}, 0.032 \mathrm{mmol})$ and 1-azido-6-methoxyhexane (100 mg, 0.64 $\mathrm{mmol})$ in toluene $(0.3 \mathrm{~mL})$ and stirred for 3 days at room temperature. Aliquots were drawn after $6 \mathrm{~h}, 1$, and 3 days and analyzed by ${ }^{1} \mathrm{H}$ NMR. From a set of NMR spectra shown below, we found that there was no significant change in the chemical structure of model compound, 1-azido-6-methoxyhexane, under the same condition of the polymerization in this work. In specific, we calculated the integration value for each representative peak and there was no meaningful deviation from the theoretical value. 


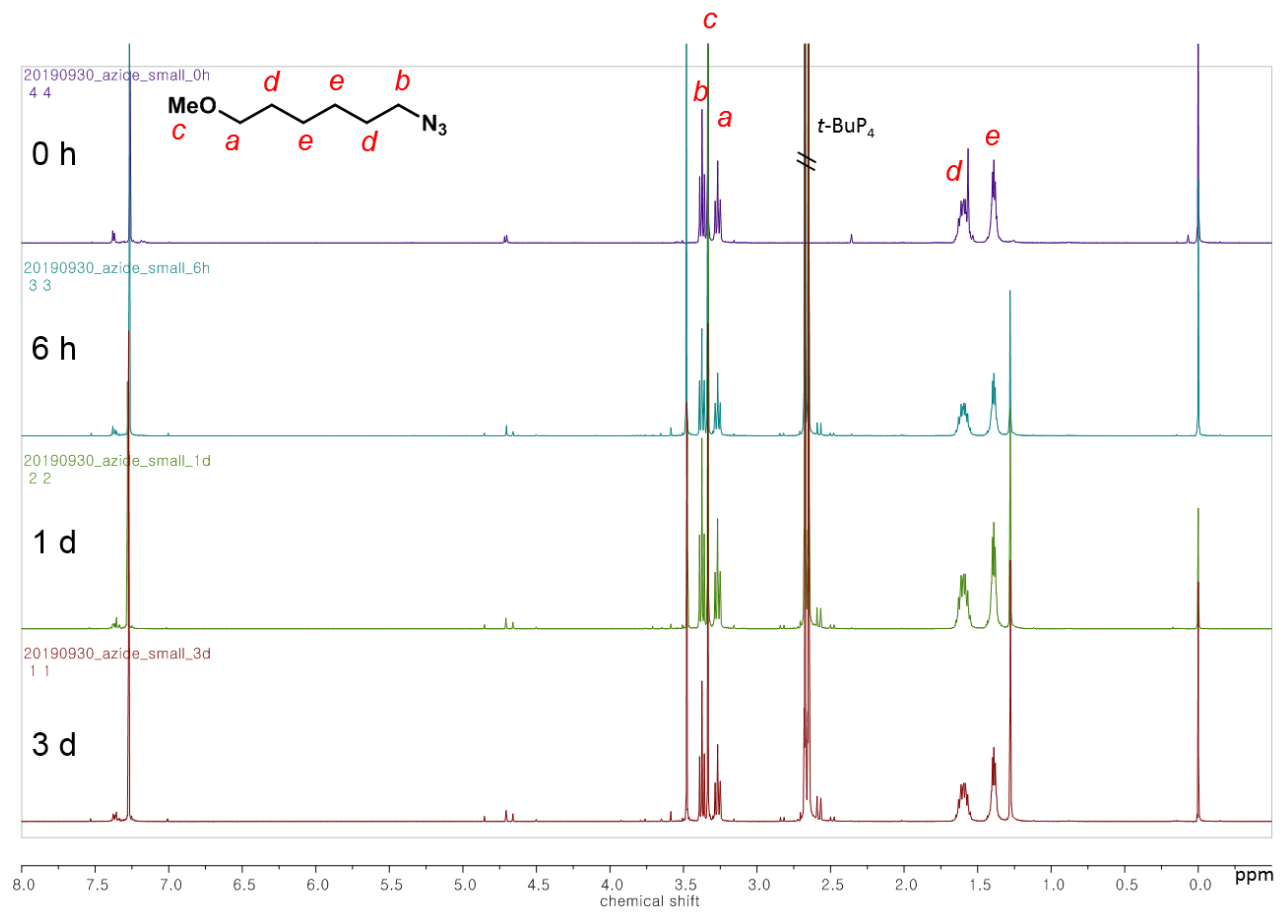

Figure S27. ${ }^{1} \mathrm{H}$ NMR spectra of the reaction mixture of 1-azido-6-methoxyhexane with $t$-BuP 4 and benzyl alcohol over 3 days at room temperature $\left(400 \mathrm{MHz}, \mathrm{CDCl}_{3}\right)$.

Table S1. ${ }^{1} \mathrm{H}$ NMR Integration Values of 1-Azido-6-Methoxyhexane Under AROP

\section{Condition}

\begin{tabular}{ccccccc} 
& \multirow{2}{*}{$\begin{array}{c}\text { \# of } \\
\text { Peak }\end{array}$} & $\begin{array}{c}\text { Integration region } \\
(\mathrm{ppm})\end{array}$ & \multicolumn{5}{c}{ Integration value } \\
\cline { 4 - 7 } & & & $0 \mathrm{~h}$ & $6 \mathrm{~h}$ & $1 \mathrm{~d}$ & $3 \mathrm{~d}$ \\
$\mathrm{a}$ & 2 & $3.229-3.302$ & 2.15 & 2.08 & 2.10 & 2.06 \\
$\mathrm{~b}$ & 2 & $3.045-3.349$ & 2.05 & 2.05 & 2.07 & 2.04 \\
$\mathrm{c}$ (ref.) & 3 & $3.315-3.347$ & 3.00 & 3.00 & 3.00 & 3.00 \\
$\mathrm{~d}$ & 4 & $1.516-1.674$ & 4.89 & 4.22 & 4.24 & 4.22 \\
$\mathrm{e}$ & 4 & $1.324-1.461$ & 4.33 & 4.30 & 4.31 & 4.31
\end{tabular}


Representative $^{1} \mathrm{H}$ NMR Spectra of P(AEGE) and P(ABGE)

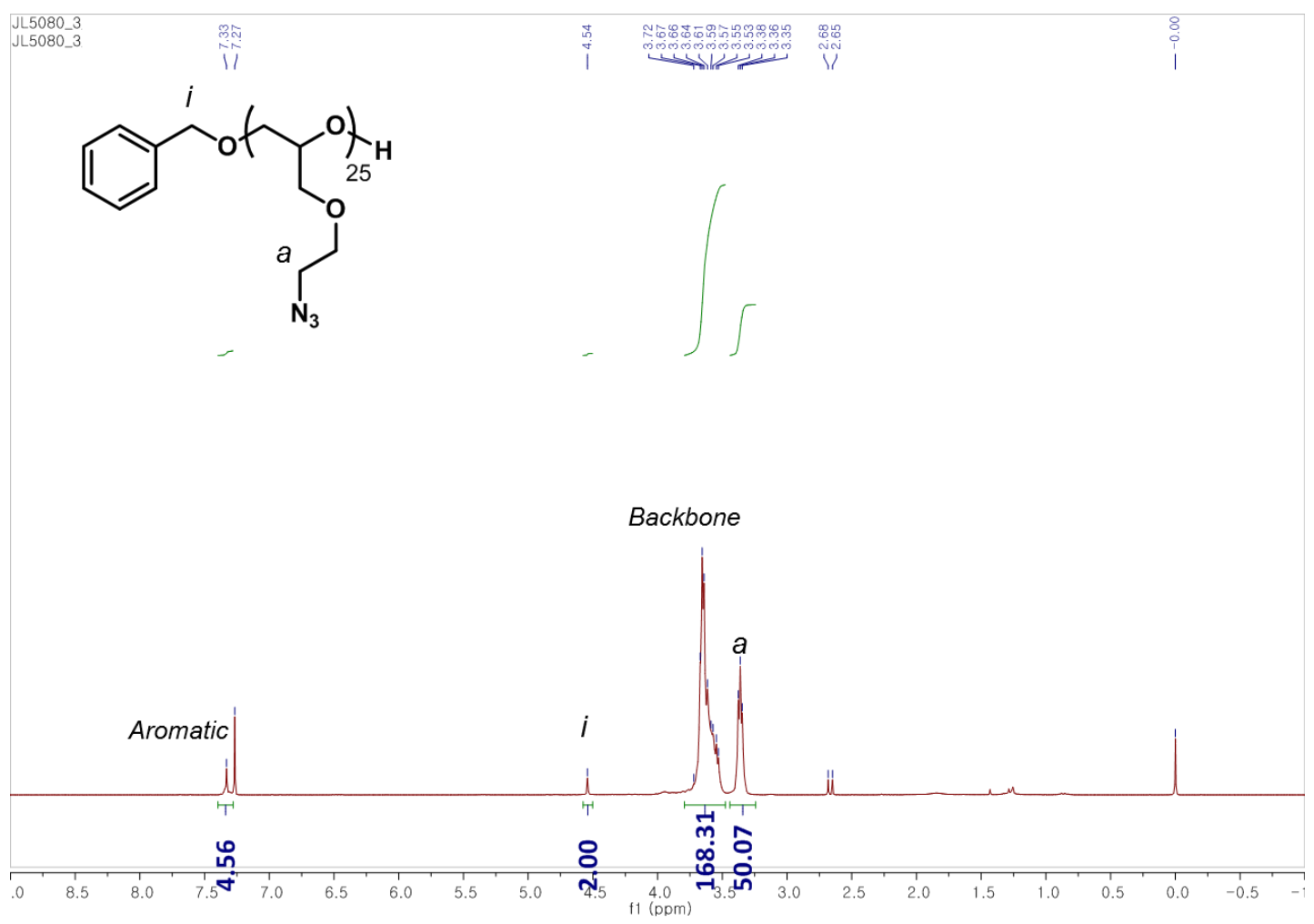

Figure S28. Representative ${ }^{1} \mathrm{H}$ NMR spectrum of $\mathbf{E 2}$ in $\mathrm{CDCl}_{3}$.

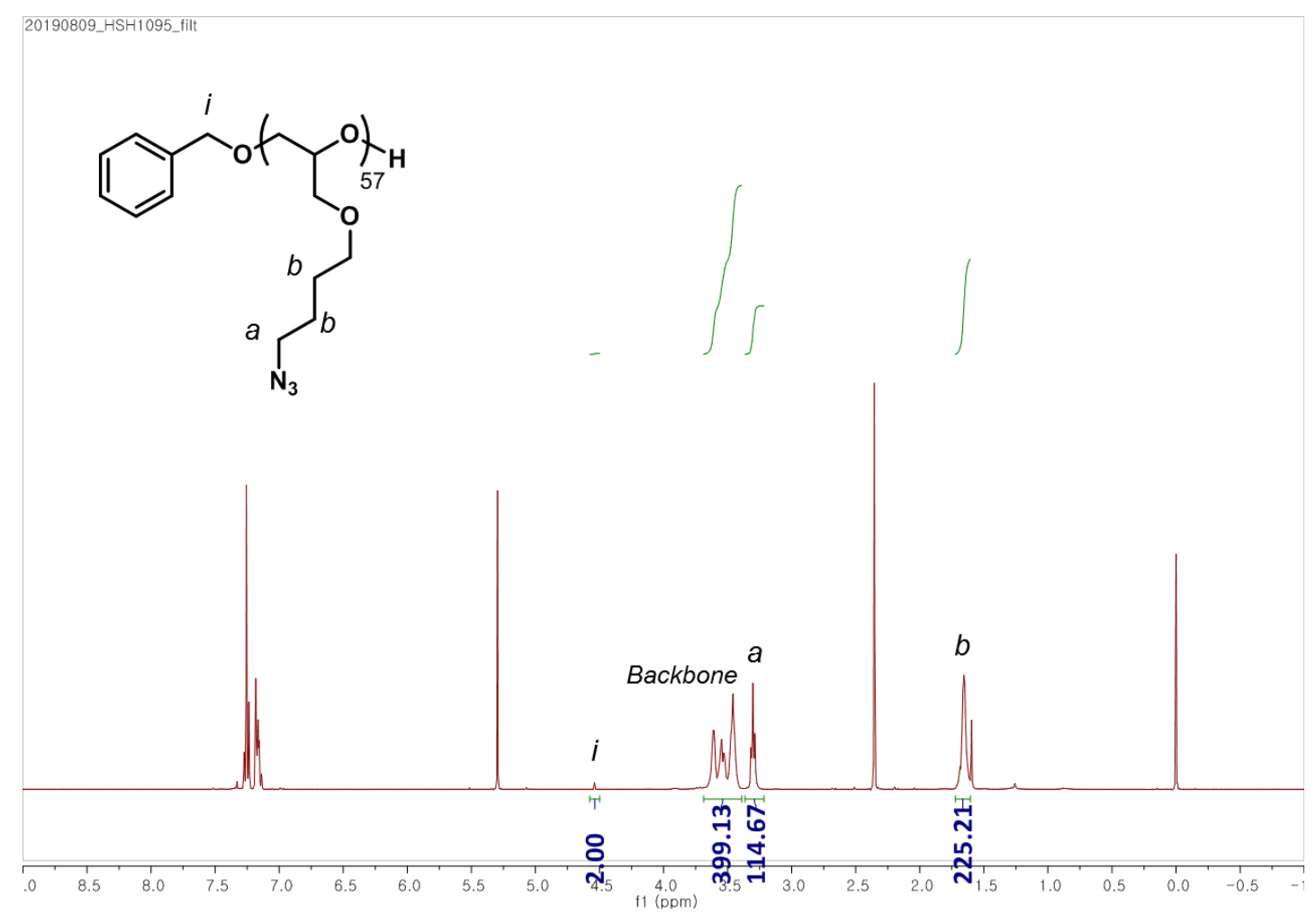

Figure S29. Representative ${ }^{1} \mathrm{H}$ NMR spectrum of $\mathbf{B} 2$ in $\mathrm{CDCl}_{3}$. 


\section{Results of in situ ${ }^{1} \mathrm{H}$ NMR Polymerization Kinetics Study}

a)

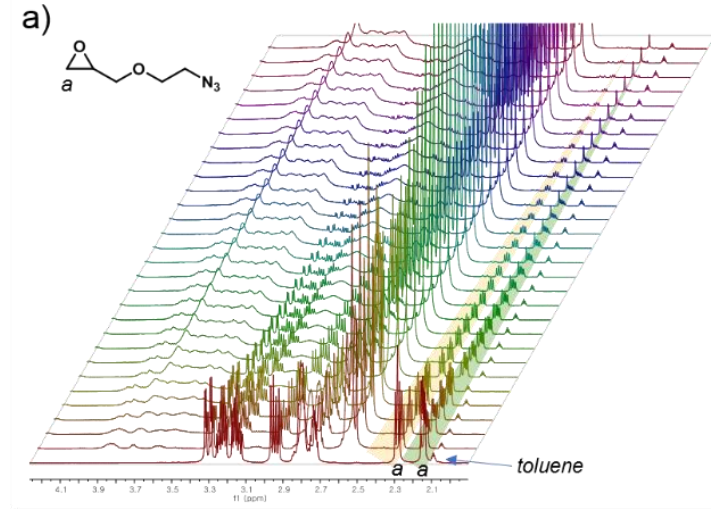

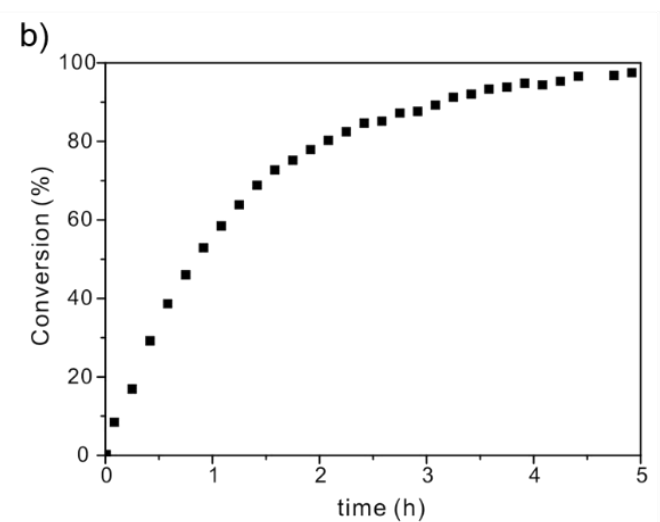

Figure S30. (a) In situ monitoring of the homopolymerization kinetics of AEGE. (b) Conversion versus time for the homopolymerization of AEGE.

a)

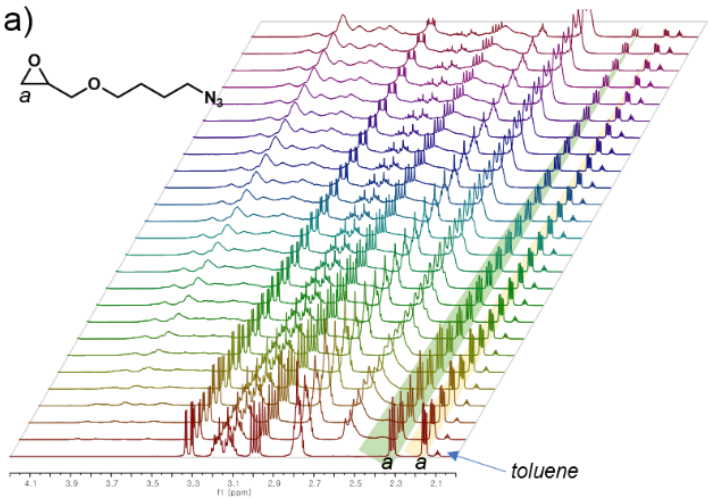

b)

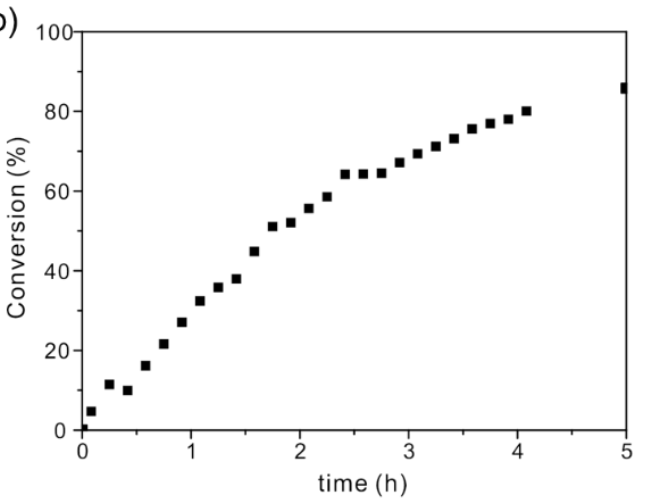

Figure S31. (a) In situ monitoring of the homopolymerization kinetics of ABGE. (b) Conversion versus time for the homopolymerization of ABGE.
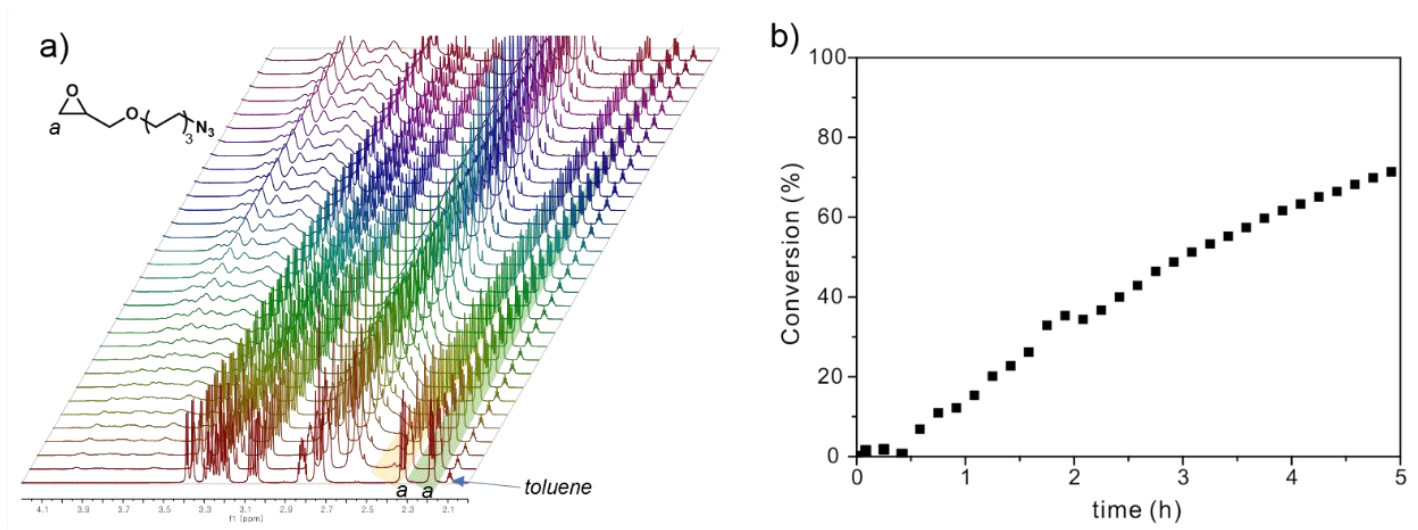

Figure S32. (a) In situ monitoring of the homopolymerization kinetics of AHGE. (b) Conversion versus time for the homopolymerization of AHGE. 
The Effect of Hydrophobicity on Polymerization Rate

Table S2. Calculated $\log P$ Values and Polymerization Rate Data

$\begin{array}{ccc}\text { Monomer } & \log P & \begin{array}{c}\text { Polymerization rate } \\ \left(k, 10^{-3} \mathrm{~min}^{-1}\right)\end{array} \\ \text { AEGE } & 1.19 & 12.4 \\ \text { ABGE } & 1.94 & 6.47 \\ \text { AHGE } & 2.60 & 4.02\end{array}$

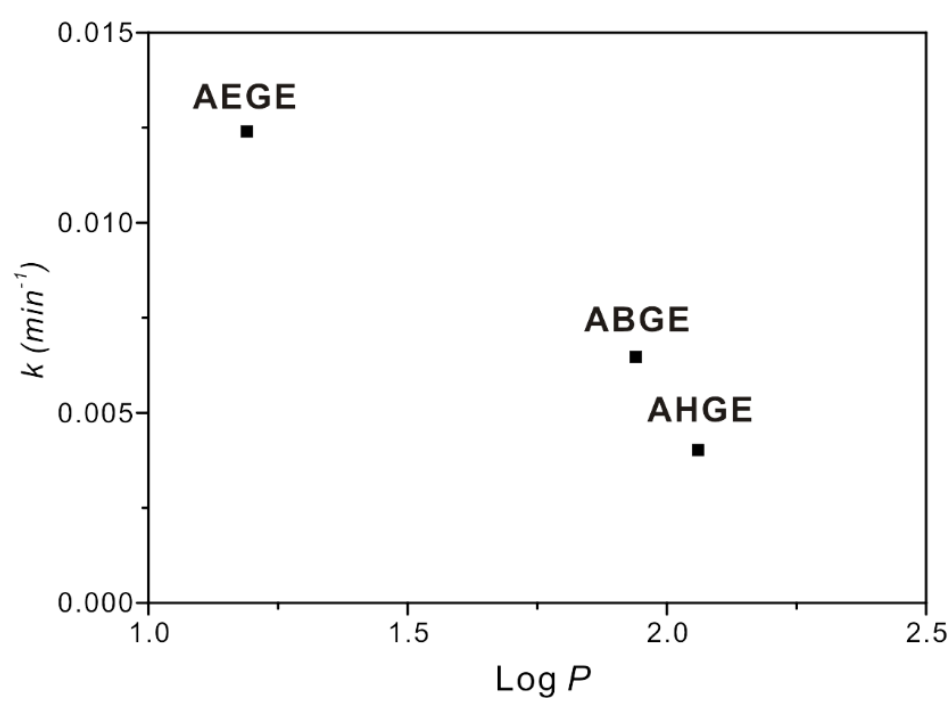

Figure S33. Correlation of calculated $\log P$ and polymerization rate of monomers. 
FT-IR Spectra of Polymers after CuAAC

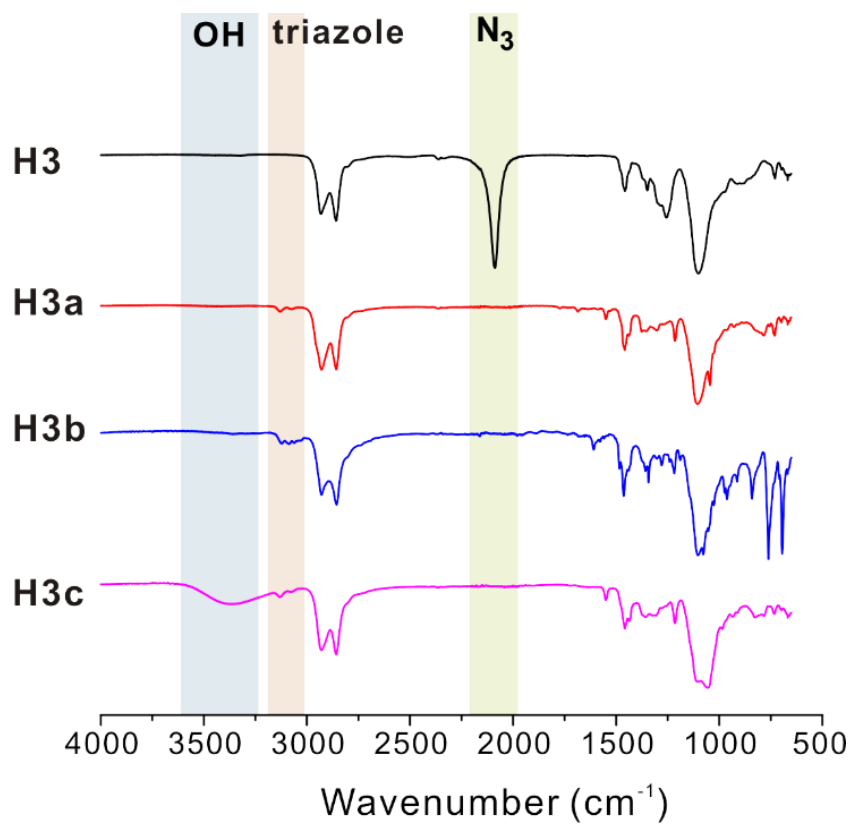

Figure S34. FT-IR spectra of H3, H3a, H3b and H3c.

${ }^{1}$ H NMR Spectra of Reduced Polymers (H2a-H2c and PAm)

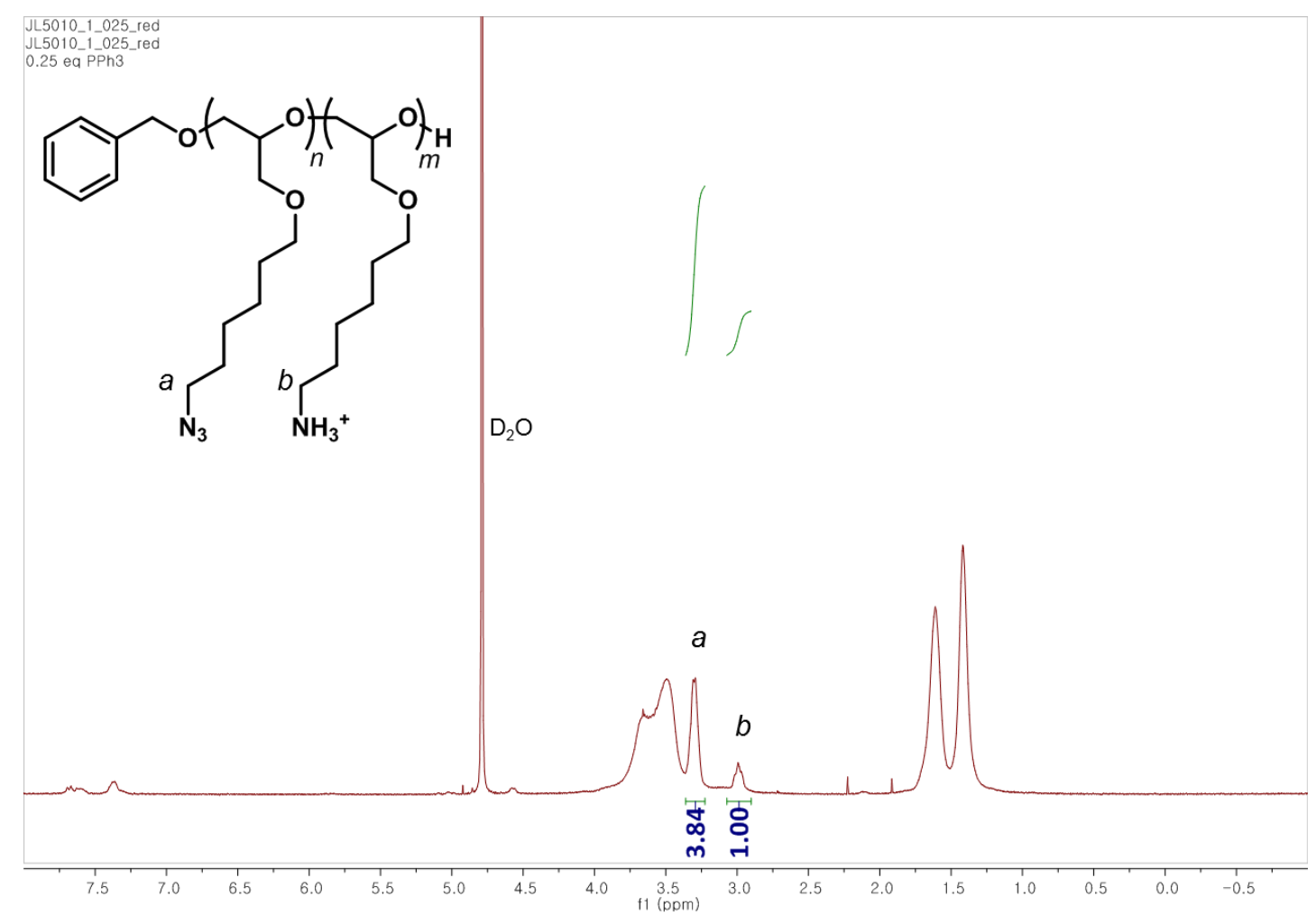

Figure S35. ${ }^{1} \mathrm{H}$ NMR spectrum of $\mathbf{H 2 a}$ in $\mathrm{D}_{2} \mathrm{O}$. 


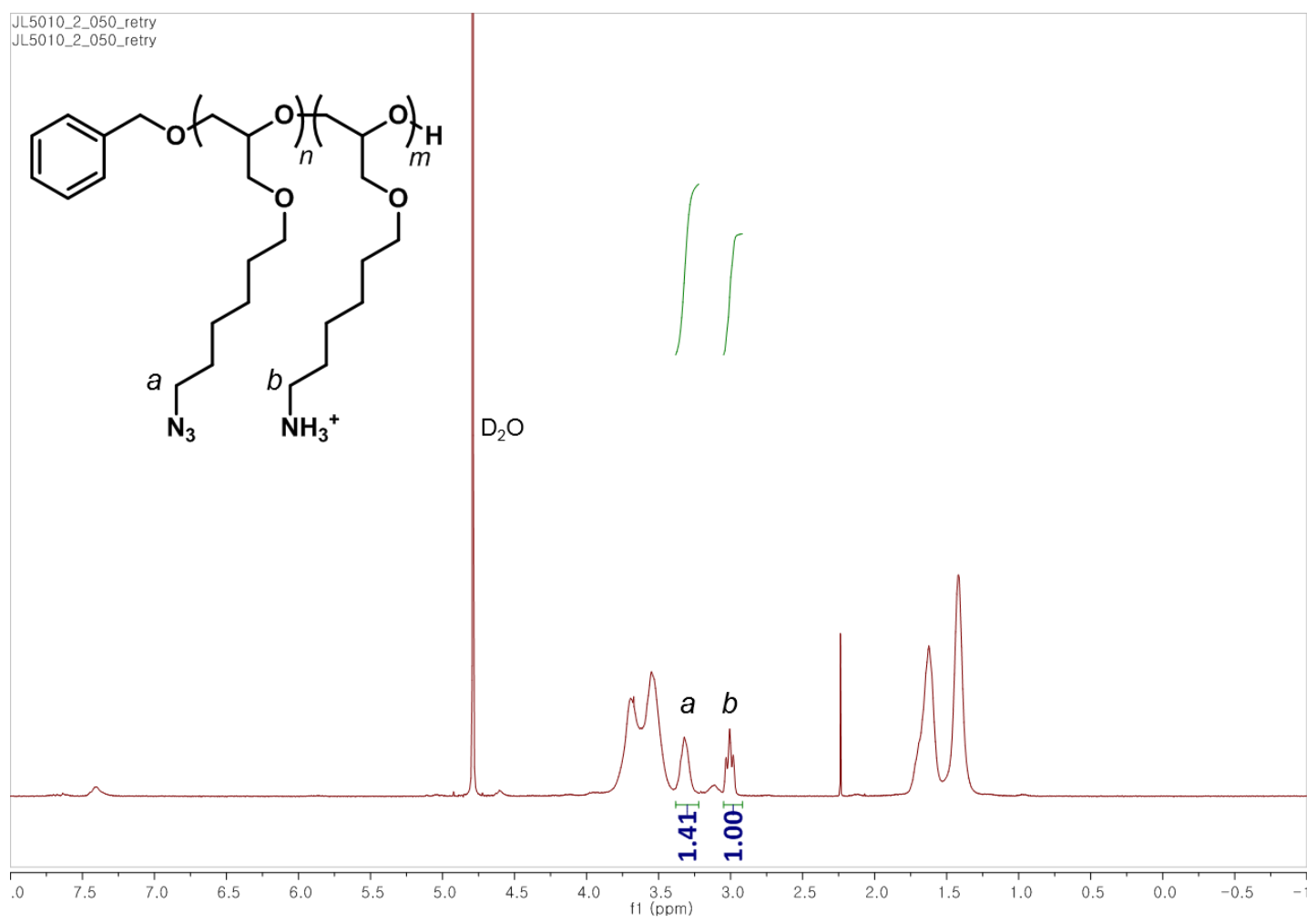

Figure S36. ${ }^{1} \mathrm{H}$ NMR spectrum of $\mathbf{H 2 b}$ in $\mathrm{D}_{2} \mathrm{O}$.

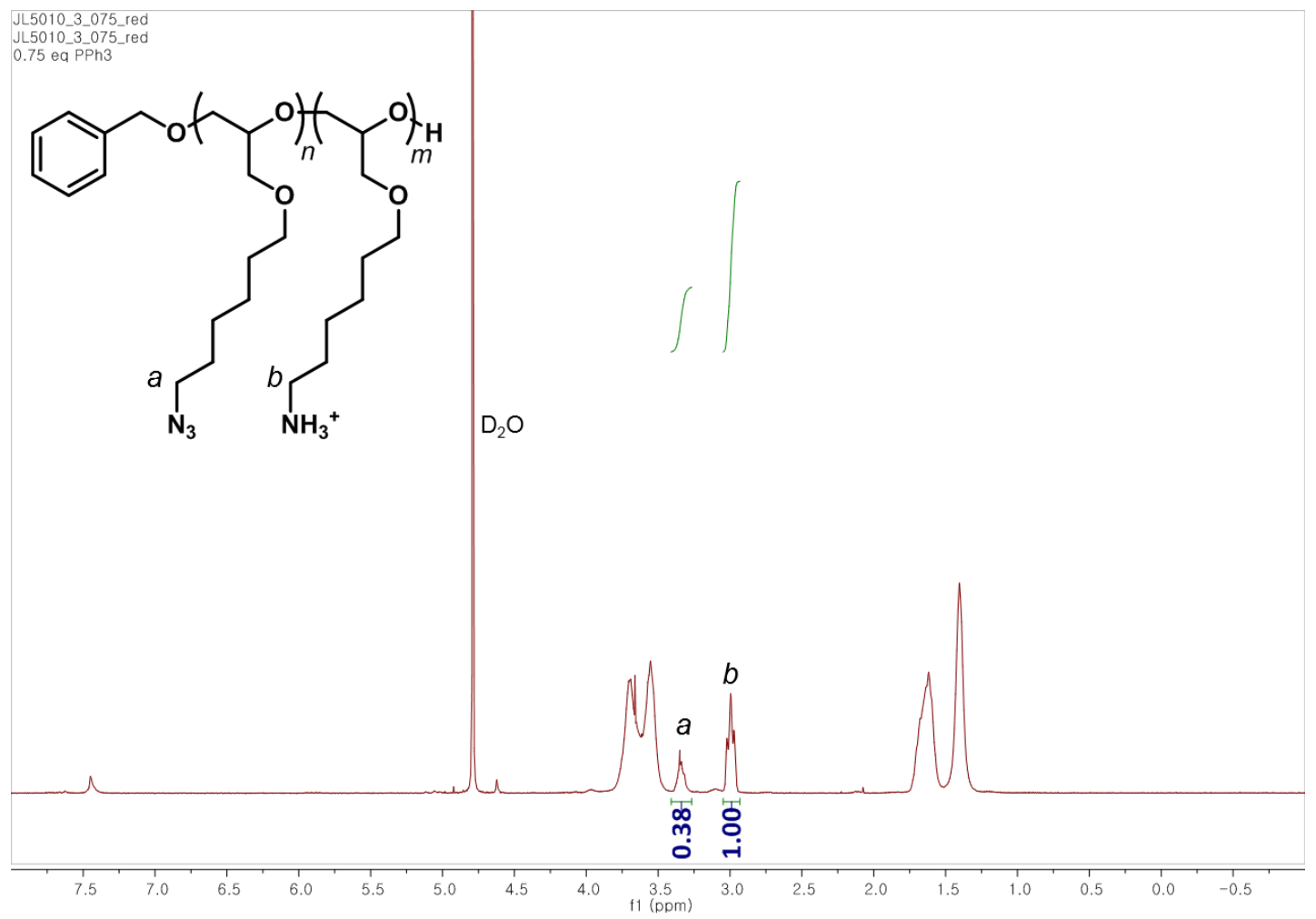

Figure S37. ${ }^{1} \mathrm{H}$ NMR spectrum of $\mathbf{H 2 c}$ in $\mathrm{D}_{2} \mathrm{O}$. 


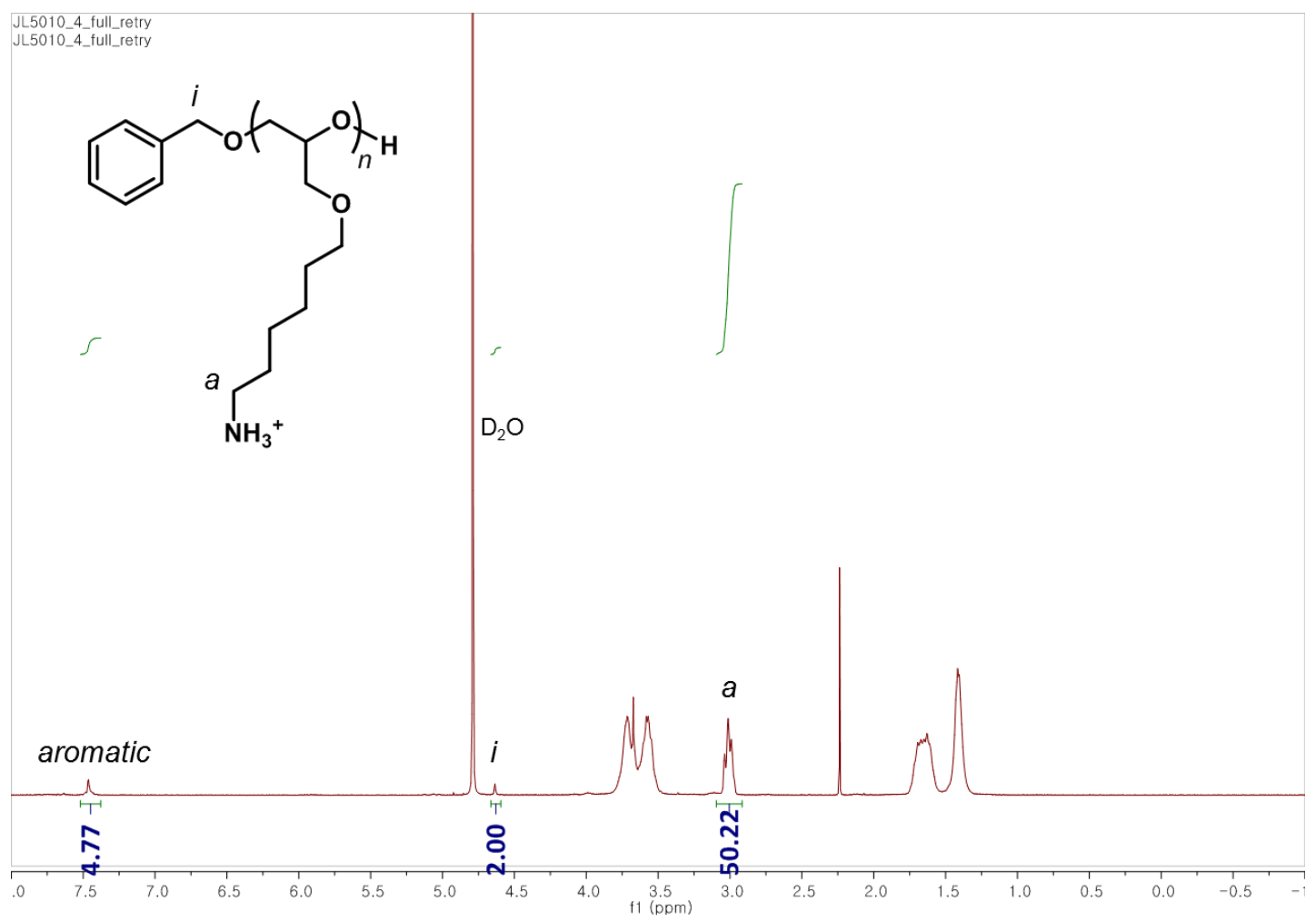

Figure S38. ${ }^{1} \mathrm{H}$ NMR spectrum of $\mathbf{H A m}$ in $\mathrm{D}_{2} \mathrm{O}$. 
${ }^{1} \mathrm{H}$ NMR Spectra of P(AHGE)- $b$-P(AGE) and P(AHGE-co-AGE)

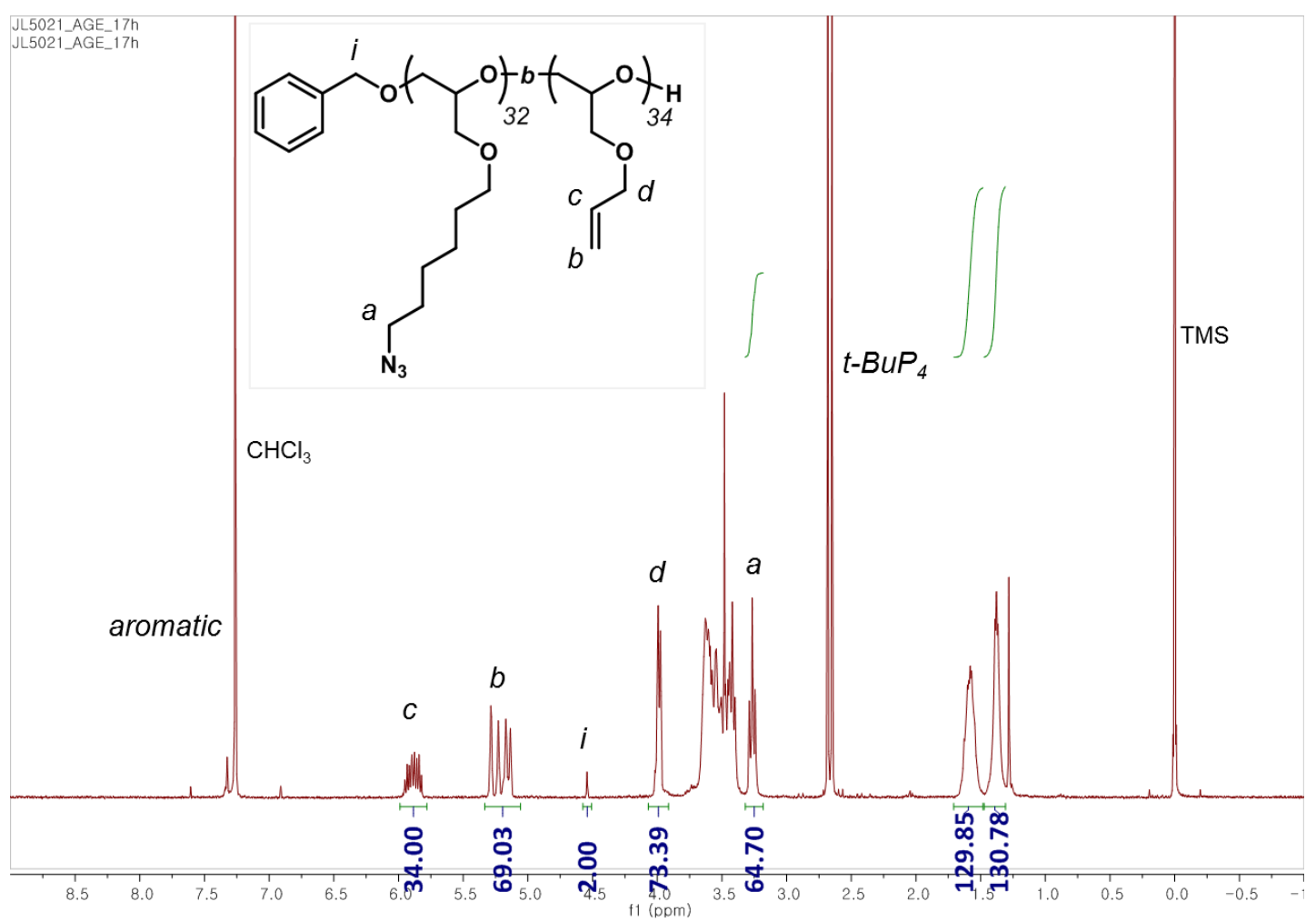

Figure S39. The crude ${ }^{1} \mathrm{H}$ NMR spectrum of $\mathrm{P}(\mathrm{AHGE})-b-\mathrm{P}(\mathrm{AGE})$.

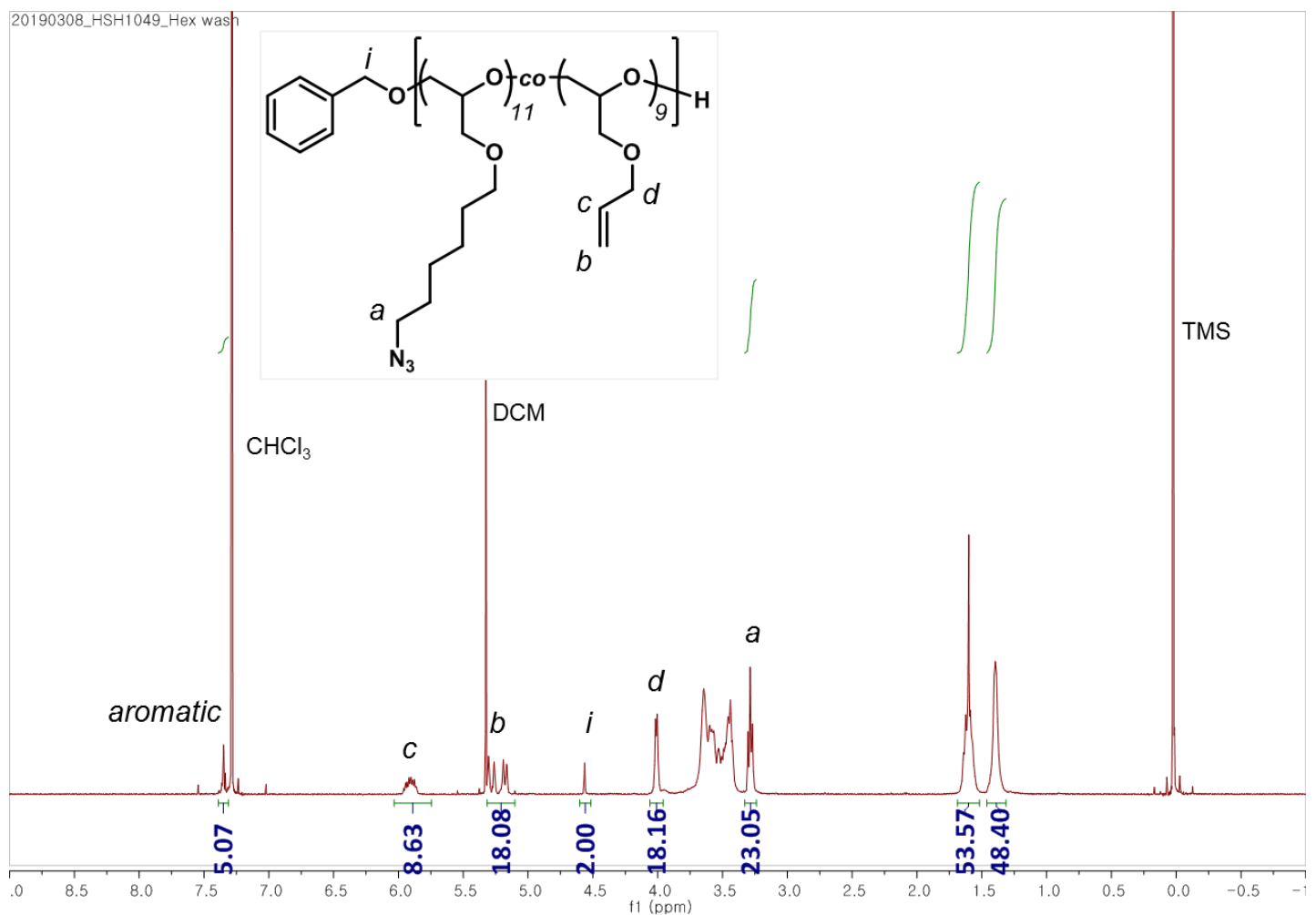

Figure S40. ${ }^{1} \mathrm{H}$ NMR spectrum of $\mathrm{P}(\mathrm{AHGE}-$ - o-AGE). 


\section{Additional Data and Experimental Procedures}

Table S3. Results of Copolymerizations using AHGE and AGE

$\begin{array}{ccc}\text { Polymer } & \begin{array}{c}\text { Feed ratio } \\ ([\mathrm{AHGE}] /[\mathrm{AGE}])\end{array} & \begin{array}{c}\text { Degree of Polymerization } \\ ([\mathrm{AHGE}] /[\mathrm{AGE}])^{a}\end{array} \\ \mathrm{P}(\mathrm{AHGE})-b-\mathrm{P}(\mathrm{AGE}) & 30 / 30 & 32 / 34 \\ \mathrm{P}(\mathrm{AHGE}-\mathrm{co}-\mathrm{AGE}) & 10 / 10 & 11 / 9\end{array}$

${ }^{a}$ Determined from ${ }^{1} \mathrm{H}$ NMR spectra of the resulting polymers

Synthesis of $\boldsymbol{H} 3 \boldsymbol{b}$ by CuAAC. This polymer was prepared using phenylacetylene as a functional alkyne, according to the general procedure with $\mathrm{CuBr}$ and PMDETA in THF, to give $110 \mathrm{mg}(95 \%)$ of a yellow polymer.

Synthesis of $\mathbf{H 3 c}$ by CuAAC. $\mathbf{H 3}$ (80 mg, $0.39 \mathrm{mmol}$ of azides, $1.0 \mathrm{eq}$ ) and 5-hexyn-1ol $(65.1 \mu \mathrm{L}, 0.59 \mathrm{mmol}, 1.5 \mathrm{eq})$ were dissolved in $3 \mathrm{~mL}$ of $\mathrm{THF}$ in a $20 \mathrm{~mL}$ reaction tube. The solution was degassed by $\mathrm{N}_{2}$ bubbling for $30 \mathrm{~min} . \mathrm{CuBr}(5.59 \mathrm{mg}, 0.039 \mathrm{mmol}, 0.10 \mathrm{eq})$ and $N, N, N$ ', $N$ "' $N$ ”'-pentamethyldiethylenetriamine (PMDETA) $(8.14 \mu \mathrm{L}, 0.039 \mathrm{mmol}, 0.10 \mathrm{eq})$ were added to the mixture and the solution was stirred for $2 \mathrm{~h}$ at room temperature. Upon precipitation of the polymer from the reaction solution, the solvent was carefully decanted and the residue was dissolved in $\mathrm{MeOH}$ and precipitated in a saturated aqueous ammonium chloride solution. The aqueous layer was decanted, and the polymer was dried under vacuum to give 98 $\mathrm{mg}(83 \%)$ of a transparent viscous polymer.

Staudinger reduction for $\boldsymbol{H} 2 \boldsymbol{b}$. $\mathbf{H 2}$ (100 mg, $0.49 \mathrm{mmol}$ of azide, $1.0 \mathrm{eq})$ was dissolved in $1 \mathrm{~mL}$ of THF and the solution was degassed by $\mathrm{N}_{2}$ bubbling for $20 \mathrm{~min}$. $\mathrm{PPh}_{3}(64.26 \mathrm{mg}$, $0.245 \mathrm{mmol}, 0.50 \mathrm{eq})$ was completely dissolved in the solution. Water $(0.05 \mathrm{~mL})$ was added to the mixture and the solution was stirred for $12 \mathrm{~h}$ at room temperature. THF was removed under reduced pressure and $1.0 \mathrm{M} \mathrm{HCl}$ solution was added to acidify and dissolve the polymer. The 
mixture was washed 3 times with diethyl ether to remove residual triphenylphosphine (TPP) and triphenylphosphine oxide (TPPO). The aqueous phase was lyophilized to give $110 \mathrm{mg}$ of a white powder.

Staudinger reduction for $\mathbf{H} 2 \boldsymbol{c} . \quad \mathbf{H 2}(100 \mathrm{mg}, 0.49 \mathrm{mmol}$ of azide, $1.0 \mathrm{eq})$ was dissolved in $1 \mathrm{~mL}$ of THF and the solution was degassed by $\mathrm{N}_{2}$ bubbling for $20 \mathrm{~min} . \mathrm{PPh}_{3}$ (96.79 $\mathrm{mg}, 0.369 \mathrm{mmol}, 0.75 \mathrm{eq})$ was completely dissolved in the solution. Water $(0.05 \mathrm{~mL})$ was added to the mixture and the solution was stirred for $12 \mathrm{~h}$ at room temperature. THF was removed under reduced pressure and $1.0 \mathrm{M} \mathrm{HCl}$ solution was added to acidify and dissolve the polymer. The mixture was washed 3 times with diethyl ether to remove residual triphenylphosphine (TPP) and triphenylphosphine oxide (TPPO). The aqueous phase was lyophilized to give $100 \mathrm{mg}$ of a white powder.

Staudinger reduction for $\mathbf{H A m}$. $\mathbf{H 2}(100 \mathrm{mg}, 0.49 \mathrm{mmol}$ of azide, $1.0 \mathrm{eq})$ was dissolved in $1 \mathrm{~mL}$ of THF and the solution was degassed by $\mathrm{N}_{2}$ bubbling for $20 \mathrm{~min}$. $\mathrm{PPh}_{3}(257.04 \mathrm{mg}$, $0.98 \mathrm{mmol}, 2.0 \mathrm{eq})$ was completely dissolved in the solution. Water $(0.05 \mathrm{~mL})$ was added to the mixture and the solution was stirred for $12 \mathrm{~h}$ at room temperature. THF was removed under reduced pressure and $1.0 \mathrm{M} \mathrm{HCl}$ solution was added to acidify and dissolve the polymer. The mixture was washed 3 times with diethyl ether to remove residual triphenylphosphine (TPP) and triphenylphosphine oxide (TPPO). The aqueous phase was lyophilized to give $110 \mathrm{mg}$ of viscous polymer.

\section{Reference}

(S1) Gharakhanian, E. G.; Deming, T. J. Versatile Synthesis of Stable, Functional Polypeptides via Reaction with Epoxides. Biomacromolecules 2015, 16, 1802-1806. 